\title{
Chlorophyll fluorescence, photochemical reflective index and normalized difference vegetative index during plant senescence.
}

\author{
Gabriela Cordon $^{* a}$, M. Gabriela Lagorio ${ }^{\mathrm{b}}$ and José M. Paruelo ${ }^{\mathrm{c}}$
}

a- IFEVA, Universidad de Buenos Aires, CONICET, Facultad de Agronomía, Buenos Aires, Argentina - Área de Educación Agropecuaria, Facultad de Agronomía. Universidad de Buenos Aires.

b- INQUIMAE, Universidad de Buenos Aires, CONICET, Facultad de Ciencias Exactas y Naturales, Buenos Aires, Argentina - Dpto. de Química Inorgánica, Analítica y Química Física. Facultad de Ciencias Exactas y Naturales. Universidad de Buenos Aires. c- IFEVA, Universidad de Buenos Aires, CONICET, Facultad de Agronomía, Buenos Aires, Argentina - Dpto. de Métodos Cuantitativos y Sistemas de Información. Facultad de Agronomía. Universidad de Buenos Aires - IECA, Facultad de Ciencias, Universidad de la República. Montevideo. Uruguay.

*Corresponding author. E-mail: gcordon@agro.uba.ar

Keywords: Photochemical Reflectance Index; Normalized Difference Vegetation Index; Suninduced Chlorophyll Fluorescence; Radiation Use Efficiency; Photosynthetic parameters; Senescence

\begin{abstract}
The relationship between the Photochemical Reflectance Index (PRI), Normalized Difference Vegetation Index (NDVI) and chlorophyll fluorescence along senescence was investigated in this work. Reflectance and radiance measurements were performed at canopy level in grass
\end{abstract}


species presenting different photosynthetic metabolism: Avena sativa (C3) and Setaria italica (C4), at different stages of the natural senescence process. Sun induced-chlorophyll fluorescence at $760 \mathrm{~nm}\left(\mathrm{SIF}_{760}\right)$ and the apparent fluorescence yield $\left(\mathrm{SIF}_{760} / \mathrm{a}\right.$, with a= irradiance at time of measurement) were extracted from the radiance spectra of canopies using the Fraunhofer Line Discrimination-method. The photosynthetic parameters derived from Kautsky kinetics and pigment content were also calculated at leaf level.

Whilst stand level NDVI patterns were related to changes in the structure of canopies and not in pigment content, stand level PRI patterns suggested changes both in terms of canopy and of pigment content in leaves. Both $\mathrm{SIF}_{760} / \mathrm{a}$ and $\Phi_{\mathrm{PSII}}$ decreased progressively along senescence in both species. A strong increment in NPQ was evident in A. sativa while in S. italica NPQ values were lower. Our most important finding was that two chlorophyll fluorescence signals, $\Phi_{\mathrm{PSII}}$ and $\mathrm{SIF}_{760} / \mathrm{a}$, correlated with the canopy PRI values in the two grasses assessed, even when tissues at different ontogenic stages were present. Even though significant changes occurred in the Total Chlr/Car ratio along senescence in both studied species, significant correlations between PRI and chlorophyll fluorescence signals might indicate the usefulness of this reflectance index as a proxy of photosynthetic RUE, at least under the conditions of this study. The relationships between stand level PRI and the fluorescence estimators $\left(\Phi_{\mathrm{PSII}}\right.$ and $\left.\mathrm{SIF}_{760} / \mathrm{a}\right)$ were positive in both cases. Therefore, an increase in PRI values as in the fluorescence parameters would indicate higher RUE.

\section{Introduction}

Net Primary Production (NPP), the rate of net $\mathrm{C}$ gains of vegetation, is a key functional attribute of ecosystems (McNaughton et al., 1989) During the last two decades, major improvements on NPP estimation have been made through the use of remotely sensed data (Running et al., 2000; Hilker et al., 2008). Remote sensing estimates of C gains rely on a 
simple model, proposed by Monteith, which states that $\mathrm{C}$ gains is the product of the absorbed photosynthetically active radiation (APAR) by vegetation and the efficiency with which this radiation can be converted into biomass (Radiation Use Efficiency, RUE) (Monteith, 1972; 1977). APAR, in turn, results from the product of the incoming photosynthetically active radiation (PAR) and the fraction of PAR absorbed by green tissues (fPAR). Different studies showed a tight relationship between fPAR and spectral indices derived from the red and infrared reflectance of the surface (Sellers et al., 1992; Di Bella et al., 2004). The Normalized Difference Vegetation Index (NDVI) is the most widely used spectral index and the base of several primary production monitoring systems (Gilmanov et al., 2005; Grigera et al., 2007). Perhaps, the major shortcoming in the use of Monteith model is the estimation of RUE (Hilker et al., 2008; Martinez et al., 2013). Field estimates are difficult to derive and data extrapolation in space and time has many uncertainties (Piñeiro et al., 2006; Oyarzabal et al., 2010). Different factors related to structural and functional differences among species and different types of stressors may modify the amount of $\mathrm{C}$ fixed per MJ of PAR absorbed at the canopy level (Schurr and Rascher, 2006; Grace et al., 2007; Hilker et al., 2008). Ontogenic changes and senescence are also major controls of RUE (Hall et al., 1995).

Light energy absorbed by leaves that is not used in the process of photosynthesis must be discharged, to prevent damage in the photosynthetic apparatus (Demmig et al., 1987; Demmig-Adams and Adams, 1996). Therefore, another way of interpreting the photosynthetic RUE is as the ratio between the energy used in photochemical quenching and the energy dissipated by the two non-photochemical pathways: fluorescence emission and non radiative decay (heat loss).

The group of pigments called xanthophylls is involved in a specific biochemical process called xanthophyll cycle which has the ability to dissipate energy through the nonphotochemical quenching (NPQ), consequently, avoiding photooxidative damage. This 
facultative mechanism is called photoprotection (Demmig et al., 1987; Demmig and Adams, 1996). Gamon and collaborators (1992) developed the Photochemical Reflectance Index (PRI), which was initially employed to estimate rapid changes in the relative levels of the pigments in the xanthophyll cycle, from the differences observed in the reflectance spectral signal around $531 \mathrm{~nm}$ (Gamon et al., 1992; Peñuelas et al., 1995; Gamon et al., 1997). PRI compares the reflectance at $531 \mathrm{~nm}$ with a reference set at $570 \mathrm{~nm}$. The first band not only gives evidence of rapid changes related to light energy distribution, carried out by the xanthophyll cycle (Gamon et al., 2015), but also belongs to a spectral region characterized by absorption of carotenoids and chlorophyll. The reference band, on the other hand, is only related to the chlorophyll absorption (Gamon et al., 1992). Nowadays, it is widely recognized that depending on the time scale in which the studies are developed, changes in PRI may show different plant functions. In a diurnal timescale, PRI variations assess changes in the pigments levels of the xanthophyll cycle (facultative response). On the other hand, in studies at large temporal or spatial scales, PRI is mostly influenced by the Chlorophylls/Carotenoids ratio (constitutive response) (Sims and Gamon, 2002; Filella et al., 2009; Gamon et al, 2015). In a very recent work Gamon et al., 2015 pointed out that both, the facultative and the constitutive response of PRI are strongly correlated with the photosynthetic activity over different timescales and by means of different mechanisms.

Several authors reported that PRI has strongly correlated with RUE both at leaf (Gamon et al., 1992; 1997; Peñuelas et al., 1995) and ecosystem levels (Trotter et al., 2002; Nichol et al., 2006; Grace et al., 2007). This is because changes at short temporal scale are closely related to fast redistribution of light energy associated with photosystem II (Gamon et al., 1997; Gamon et al., 2015). Furthermore, Filella and colleagues (2009), in a study where PRI was evaluated in both temporal scales, found a strong influence of Carotenoid/Chlorophyll ratio on PRI in the long-term. In this case, they still considered PRI 
as an effective reflectance index capable of measuring changes in photosynthetic RUE in response to stress. They argued that, in addition to xanthopylls, carotenoids as $\beta$-carotene or lutein are also related to photoprotective processes. For this reason they hold that PRI might still be useful for assessment of photosynthetic RUE to the extent that RUE is correlated with Carotenoid/Chlorophyll ratio (Sims and Gamon, 2002; Filella et al., 2009). In a comprehensive review of the existing literature on PRI, Garbulsky et al. concluded that this index is a reliable estimator of the ecophysiological variables related to photosynthetic efficiency at leaf and canopy levels in a wide variety of species, functional types and temporal scales (Garbulsky et al., 2011).

Some authors suggested that it is not possible to monitor a dynamic physiological process such as $\mathrm{C}$ gain using only the reflectance of vegetation, and simultaneously emphasized the potential of chlorophyll fluorescence emission to estimate directly the photosynthetic RUE. At the same time, chlorophyll fluorescence provides very specific information about the vitality of plants and productivity (Cordon and Lagorio, 2007; Malenovský et al., 2009; Hmimina et al., 2013). Recent studies have shown that passive remote sensing techniques such as measurement of chlorophyll fluorescence induced by sunlight (sun induced fluorescence, SIF), which is modulated by the photosynthetic efficiency, should improve the knowledge of $\mathrm{CO}_{2}$ assimilation processes (Pedrós et al., 2010; Moya et al., 2004; Louis et al., 2005; Damm et al., 2010). SIF techniques are suitable for studying the efficiency of photosynthetic processes at canopy level (Malenovský et al., 2009) and, hence, a promising alternative to quantify RUE directly (Damm et al., 2010).

Field canopies include not only a combination of structurally and functionally different species but also tissues at different ontogenic stages. Understanding the influence of species composition and ontogeny on RUE at canopy level is critical to improve $\mathrm{C}$ gain 
estimations from models based on remotely sensed data. Based on this observation, the aims of this work were:

1) to investigate the relationship between PRI and chlorophyll fluorescence since both would allow valuable estimates of RUE. This was assessed at two levels, leaf and stand levels, along the natural senescence process and in species with different photosynthetic metabolism.

2) to analyze if changes in the pigment pool (mainly in Chlorophyll/Carotenoid ratio) related to ontogeny, and/or changes in canopy structures are responsible for the behavior of NDVI, PRI and SIF. Given the nature of this study (we performed measurements weekly throughout the natural process of plants senescence) we focused on the constitutive mechanism of the PRI index. However, this index would still give us information on RUE, as we discussed above.

3) to asses the relationship between NDVI and PRI in these grasses. Together, they could be very useful to estimate NPP from remotely sensed data using Monteith's model (Gamon et al., 2001; Gamon et al., 2015).

\section{Materials and Methods}

\subsection{Plant material and experimental conditions}

Plants of Avena sativa and Setaria italica were cultivated from seeds in pots of $30 \mathrm{~cm}$ of diameter. The pots were kept under normal field conditions, exposed to sun and watered daily. A sufficient amount of nutrients was supplied in order to avoid a potential deficiency.

Measurements began when the first panicle became evident. All measurements were carried out on sunny days, between 11 a.m. and 2 p.m. The average temperature of those days was $23{ }^{\circ} \mathrm{C}$ (temperature varied between 18 and $27^{\circ} \mathrm{C}$ ) and the average Photosynthetic Photon Flux Density (PPFD) was about $1000 \mu \mathrm{mol}$ photons $\mathrm{m}^{-2} \mathrm{~s}^{-1}$ at noon. Measurements were 
performed at leaf (reflectance, Kautsky kinetics parameters and pigments contents) and stand levels (reflectance and radiance).

Leaf-level measurements (reflectance, Kautsky kinetic parameters and pigment contents) were extended to other species. For these measurements leaves were chosen at different stages of senescence within the same individual. The plants used were Paspalum dilatatum (C4), Dactylis glomerata (C3), and Brassica napus L (C3). All of them were in excellent state of nutrition as they were supplemented with Hoagland nutrient solution (Hoagland and Arnon, 1950). Leaves of various colors (red, yellow and green) from two species of deciduous trees were also collected at the campus of the College of Agronomy (UBA): Liquidambar styraciflua and Rhus sylvestris. These leaves were kept in water until measurements, which were performed within two hours after collection.

The first fully developed leaf was always used in leaf-level measurements of Avena sativa, Setaria italica, Paspalum dilatatum, Dactylis glomerata and Brassica napus L. In the case of Liquidambar styraciflua and Rhus sylvestris, we specifically used leaves with different pigment content and, for this reason, the selected leaves were chosen according to their color.

\subsection{Pigment contents and RGB values}

The contents of chlorophyll a, chlorophyll-b and carotenoids were measured in the same leaves whose reflectance and photosynthetic parameters were determined (see sections 2.3 and 2.4). Leaves were washed with distilled water and dried with paper towels. Approximately $0.4 \mathrm{~g}$ of each leaf was weighed and the plant material was placed in a mortar containing liquid nitrogen to facilitate grinding. The pigments were then extracted from the formed powder by adding $2 \mathrm{ml}$ of a solution consisting of $80 \%$ acetone and $20 \%$ of TRIS buffer (final concentration $1 \% \mathrm{w} / \mathrm{v}$, adjusted to $\mathrm{pH}=8$ with $\mathrm{HCl}$ ), previously cooled with ice. 
The extract was centrifuged at $12,000 \mathrm{~g}$ for 3 minutes. A defined amount of the supernatant (1 $\mathrm{ml}$ ) which was diluted to $3.0 \mathrm{ml}$ was taken. The absorbance of the solution was determined as a function of wavelength using a Shimadzu Spectrophotometer UV 160A. Lastly, the concentration of pigments was calculated from the measured absorbance according to Sims and Gamon (2002). The reported value for each date is an average of 10 measurements. We

finally expressed the contents of carotenoids and chlorophylls in leaves as nmol/ $\mathrm{cm}^{2}$ of leaf, having previously determined the specific leaf area.

From the reflectance spectrum it was possible to calculate the tristimulus values XYZ. For this conversion the functions defined by the CIE standard observer were used. In this case, the spectral distribution of D65 illuminant was employed. Then, it was possible to transform XYZ values, whose components are in the nominal range $(0,1)$, into RGB values according to the equations proposed by Bruce Lindbloom. The values of R, G and B were calculated in the range of 0 to 255 in arbitrary units. The Spectral Calculator, developed by Bruce Lindbloom (http://www.brucelindbloom.com), was used for this purpose. RGB values reported are the average of 10 leaves.

\subsection{Radiance and reflectance measurements}

The leaf-level reflectance spectra were recorded with a portable spectroradiometer ASD FieldSpec Pro FR equipped with plant probe and leaf-clip accessories which allowed obtaining the spectrum of the first fully developed leaf, without cutting the plants. On each date 10 measurements were taken at leaf level. The use of the leaf-clip avoided the entrance of ambient light. Grasses, whose leaves did not cover the entire sampling area, were grouped (two or three, always the first fully developed) to cover the entire measuring area but with special care to avoid overlapping (Daughtry et al., 1989). 
We also used the portable hyperspectral spectroradiometer ASD FieldSpec Pro FR to measure both radiance and reflectance spectra at canopy level. The spectral range of this equipment varied between $350 \mathrm{~nm}$ to $2500 \mathrm{~nm}$; its spectral resolution was $3 \mathrm{~nm}$ in the range $350-1000 \mathrm{~nm}$ and $10 \mathrm{~nm}$ in the $1000-2500 \mathrm{~nm}$ region of the electromagnetic spectrum, while the sampling interval was $1.4 \mathrm{~nm}$ and $2 \mathrm{~nm}$ for each zone, respectively. The full-width half maximum (FWHM) was $5.5 \mathrm{~nm}$. The field of view of the sensor was $23^{\circ}$. During sampling we moved over the canopy made up with pots $\left(5 \mathrm{x} 5\right.$ pots) to cover the whole area $\left(2.25 \mathrm{~m}^{2}\right)$ and 10 spectra were recorded each time. From the reflectance spectra we calculated PRI as:

$$
P R I=\left(R_{531}-R_{570}\right) /\left(R_{531}+R_{570}\right)
$$

where $R_{531}$ is the reflectance at $531 \mathrm{~nm}$ and $R_{570}$ reflectance at $570 \mathrm{~nm}$. The Normalized Difference Vegetation Index (NDVI) was calculated as:

$$
N D V I=\left(R_{774}-R_{677}\right) /\left(R_{774}+R_{677}\right)
$$

in this case, $R_{677}$ is the reflectance at $677 \mathrm{~nm}$ and $R_{744}$ reflectance at $774 \mathrm{~nm}$.

The sun-induced fluorescence (SIF, hereafter) of the canopy was derived from its radiance spectrum (L) and the incident irradiance (E) at the so-called Fraunhofer lines. We used the Fraunhofer Line Discrimination (FLD) method to obtain the magnitude of the fluorescence for $\mathrm{O}_{2}$-A (Moya et al., 2004; Damm et al., 2010; Liu and Cheng, 2010). It was deduced by comparing the measured signal within the absorption band (in) with the signal measured outside it (out), which contains the solar irradiance background (Meroni et al., 2009). Incident solar irradiance (E) and the radiance of vegetation cover (L) on the bottom band (in) and on 
the shoulder of the band (out) were measured and sun induced fluorescence (SIF) was obtained according to (3):

$$
\operatorname{SIF}=\left[E\left(\lambda_{\text {out }}\right) * L\left(\lambda_{\text {in }}\right)-L\left(\lambda_{\text {out }}\right) * E\left(\lambda_{\text {in }}\right)\right] /\left[E\left(\lambda_{\text {out }}\right)-E\left(\lambda_{\text {in }}\right)\right]
$$

Moreover, the value used within the absorption band (in) was set at $760 \mathrm{~nm}$ while the signal measured outside the absorption band (out) was an average value between 750-755 $\mathrm{nm}$.

SIF has the same physical units as the radiance, $\mathrm{W} \mathrm{m}^{-2} \mathrm{~nm}^{-1} \mathrm{sr}^{-1}$. The incident solar irradiance (E) was determined using a Spectralon panel (Labsphere, Inc.) of 51 x $51 \mathrm{~cm}$. The apparent fluorescence yield (SIF/a), that is, the ratio between the SIF and the irradiance reaching the canopy at the time of measurement (a) in the edge of the observed Franhoufer line $\left(\mathrm{O}_{2}\right.$-A in this case), is a widely used parameter (Liu and Cheng, 2010). $\mathrm{SIF}_{760} / \mathrm{a}$ becomes a dimensionless number that reflects the apparent fluorescence yield regardless of the level of light reaching the coverage, while SIF signal depends linearly on the illumination intensity of PAR as demonstrated by Liu and Cheng in 2010 . We preferred to use $\mathrm{SIF}_{760} /$ a to eliminate the influence of PAR level.

An additional set of experiments was conducted in order to evaluate the fluorescence results obtained at stand level. In this case, a 3 x 4-pot (diameter $30 \mathrm{~cm}$ ) canopy was designed to simulate a small canopy with plants of Setaria italica and Cichoriun intybus. Radiance spectrum of the canopy (L) and the incident irradiance (E) obtained using the Spectralon panel were recorded. Then, the original pots of $S$. italica or $C$. intybus were replaced by an increasing number of pots containing completely dried plant material (wheat straw). Canopy PRI values were also calculated for each assembly of pots. In the first assembly we only replaced one pot with dry material, subsequently; we replaced 2, 4, 6, 8 and finally 10 pots with dried plant material (remaining only 2 pots with green plants from the original 12). On 
each assembly, 3 pots were arranged randomly and 3 radiance and irradiance spectra were recorded each time.

\subsection{Kautsky kinetics parameters}

Photochemical parameters were obtained with a modulated fluorometer Hansatech FMS1 on leaves still attached to the plants. In all cases, plants were dark-adapted for 20 minutes prior to measurements. To take into account the natural variability of leaves, at least 10 measurements on different leaves were performed and averaged. The values of initial fluorescence $\left(\mathrm{F}_{0}\right)$ were obtained illuminating the leaves with low light, and then a saturating light pulse was applied to obtain the maximum fluorescence $\left(\mathrm{F}_{\mathrm{m}}\right)$. Subsequently the leaves were exposed to actinic light to reach steady state fluorescence $\left(F_{s}\right)$. Next, a new pulse of saturating light was applied to obtain the value of maximum fluorescence of leaves adapted to light $\left(\mathrm{F}_{\mathrm{m}}{ }^{\prime}\right)$. With these data three photosynthetic parameters were calculated (equations 4-6). The maximum photochemical quantum yield is the maximum photochemical efficiency of photosystem II (PSII) obtained in dark-adapted leaves (Rosenqvist and van Kooten, 2003), equation 4:

$$
F_{v} / F_{m}=\left(F_{m}-F_{0}\right) / F_{m}
$$

The quantum efficiency of PSII is the effective quantum yield of the open PSII reaction centers. It is explained as the efficiency of PSII under the actual degree of reaction center closure (leaves adapted to light) (Rosenqvist and van Kooten, 2003), equation 5:

$$
\phi_{P S I I}=\left(F_{m}{ }^{\prime}-F_{s}\right) / F_{m}{ }^{\prime}
$$


The Stern-Volmer non-photochemical quenching parameter (NQP) is related to non-radiative dissipation as heat, equation 6:

$$
N P Q=\left(F_{m}-F_{m}{ }^{\prime}\right) / F_{m}{ }^{\prime}
$$

An increase in this parameter indicates greater thermal dissipation in PSII and it positively correlates with zeaxanthin levels in leaves (Tambussi et al., 2002).

\subsection{Statistical analyses}

Analysis of variance and Pearson correlation analysis were performed using InfoStat software (Di Rienzo et al., 2010). Correlation significance was evaluated with Fisher's test at $\alpha=0.05$. Linear regression analysis and plots were performed with Sigma Plot 10.0 (Systat Software Inc., San Jose, CA).

\section{Results and Discussions}

\subsection{Pigment content variation between species}

Statistically significant differences were observed for Avena sativa among dates for total chlorophyll (chlorophyll a + chlorophyll b, i.e. Total Chl) concentrations and for chlorophyll a (Chl a) and b (Chl b) contents separately. Ten days after measurements began, we observed a slight increase in chlorophyll. Chlorophyll did not change appreciably up to 31 days after first panicle appeared (DFPA), displaying subsequently an important decrease (see Table A in Supplementary Material, SM hereinafter).

Total carotenoid content (xanthophylls + carotenes, i.e. Car) for A. sativa varied significantly over time. It doubled since the appearance of the first panicle until the tenth day of measurements, remaining then almost constant up to 22 DFPA. From this date to day 31 an 
increase was observed. During the final stages of natural senescence, from 31 DFPA to 39 DFPA, values began to fall. We also found that the ratio of total chlorophyll to total carotenoids (Total Chl/Car) was appreciably lower at the end of the experience. $\mathrm{Chl} \mathrm{a} / \mathrm{b}$ showed the same trend as Total Chl/Car as a function of time (see Table A in SM).

Total chlorophyll content decreased during natural senescence of Setaria italica but differences were not statistically significant. The same behavior was observed for $\mathrm{Chl} a$ and $\mathrm{b}$ and for the ratio between them. Variation in carotenoid content did not follow a clear trend despite significant differences among measurement dates. The Total Chl/Car ratio presented significant differences between the two previous dates (see Table A in SM).

As expected, pigment content data showed that the breakdown of chlorophyll started before that of carotenoids in both studied species. Regarding pigments, the best indicator of the processes of senescence in this work was the ratio of total chlorophyll to total carotenoids, which is an indicator of greenness in plants (Lichtenthaler and Buschmann, 2001). This ratio usually varies between 4.2 and 5 in sunny leaves. Lower values as found here are indicators of senescence, stress or damage in the photosynthetic machinery (see Table A in SM).

Photographs of representative leaves on each date of measurement in both studied species were included to accompany the pigment data (Figure 1). Additionally, RGB values were included as an index representing leaf senescence. Photographs and RGB values altogether provided an idea of the senescent level of leaves on each measurement day.

\subsection{PRI variations between species and ontogeny: leaf and canopy level}

PRI values at stand level were negative in both species and they were always much lower than the corresponding values at leaf level (Figure 2). This pattern is consistent with previous results from literature (Barton and North, 2001). In our work this occurred because the spectral reflectance signature of canopy was contaminated with dry material reflectance 
(whose proportion increased as natural senescence progressed). The reflectance spectra of dry material had higher values at $570 \mathrm{~nm}$ than to $531 \mathrm{~nm}$ and for this reason, the canopy values of PRI were negative (see equation 1). While the whole set of values for the stand level PRI were negative, leaf PRI values began positive and then fell to negative (more marked trend in S. italica). For A. sativa an inflection point was observed 22 days after first panicle appeared when stand level PRI values began to fall with a higher slope. This downfall was due to structural changes. It was confirmed by the stand level NDVI values, which began to fall at the same time i.e. 22 DFPA (see figure 3). This date was an inflection point from which carotenoid content in leaves increased, decreasing in turn the Total Chl/Car ratio; even though the total chlorophyll content in leaves was stable for ten days. In this sense, leaf PRI values were less sensitive to changes in pigment content and began to fall from 31 DFPA (see Figure 2).

Leaf PRI values positively and significantly correlated with the stand level PRI values (Pearson correlation coefficient $=0.77, \mathrm{p}<0.05$, Pearson's correlation coefficients were included in the Table 1) as previous studies have shown in closed-canopy stands (Stylinski et al., 2002; Gamon et al., 2015 and references therein). The correlation observed supports the description of the canopy, at least for this index, in terms of the big-leaf hypothesis (Field, 1991). The big-leaf model builds from the concept that similar physical and physiological factors restrict the leaf and canopy functions in the same way (Field, 1991).

\subsection{NDVI variations between species and ontogeny: leaf and canopy level}

Stand level NDVI values were higher than their respective values at leaf level. This fact may be attributed to the enhanced multiple scattering and absorbing of multiple layers in the first case, which led to enhanced NDVI (Asner, 1998). For NDVI (as for PRI) stand level values were more sensitive to changes to senescence than the respective values at leaf level. NDVI at 
stand level decreased along time for S. italica while it remained practically unchanged at the leaf level. In the case of A. Sativa, NDVI at stand level began to decrease appreciably from the day 22 on since first panicle appeared. Conversely, leaf NDVI values increased slightly over time, (Figure 3). As the total chlorophyll content was unable to explain the changes observed (see section 3.1. and Table A in SM), we thought that in both species changes in stand level NDVI values were related to canopy structural changes. Undoubtedly an important factor was the increase in the content of dry material. In A. sativa these changes began on 22 DFPA while in S. italica changes occurred since the start of measurements. Total chlorophyll content began to decrease on 31 DFPA in A. sativa, while no significant changes were observed on the three measure dates for S. italica.

\subsection{Relationship between pigment content and NDVI and PRI}

No significant correlations were found between leaf NDVI and stand level NDVI with total chlorophyll content or with Total Chl/Car ratio for both studied species when data was analyzed separately and together. These results suggested that variation in the values of NDVI, both at leaf and stand level and for the two studied species were due to changes in canopy structure as already discussed.

On the other hand, leaf PRI correlated positively with Total Chl/Car ratio and with total chlorophyll content (Pearson' correlation coefficient: 0.73 , and 0.75 , respectively, both p $<0.05$ ) when data of both species were combined (A. sativa and S. italica) (Table 1). At stand level no correlation was evident. For leaves of other species at different stages of senescence (Paspalum dilatatum, Dactylis glomerata, Brassica napus L, Liquidambar styraciflua and Rhus sylvestris), together with the data for A. sativa and S. italica, we found a linear relationship between leaf PRI values and the log of total chlorophyll concentration (Leaf PRI $=-0.199+0.123 * \log$ Total Chl, $\left.\mathrm{R}^{2}=0.78, \mathrm{p}<0.047\right)$, and a linear relationship between leaf 
PRI and the $\log$ of Total Chl/Car ratio (Leaf PRI $=-0.076+0.116 * \log$ Total Chl/Car, $\mathrm{R}^{2}=$ $0.80, \mathrm{p}<0.045$ ) (Figure A and B in the SM, respectively). Our results and previous work (Stylinski et al., 2002; Sims and Gamon, 2002) showed that the relationship between PRI and total chlorophyll content or PRI and the Total Chl/Car ratio at leaf level is robust within a species and among them. We suspected that at the stand level these relationships broke down when the canopy structure became more heterogeneous in terms of green and senescent material.

Our results and previous studies supported the idea than the long-term signal of PRI, was influenced by pigments other than xanthophylls (Stylinski et al., 2002; Filella et al., 2009; Rahimzadeh-Bajgiran et al., 2012; Hmimina et al., 2013; Gamon and Bond, 2013; Soudani et al., 2014). The dynamics of chlorophyll content in leaves (or the Total Chl/Car ratio) could strongly question the usefulness of this index as a promising proxy of the photosynthetic radiation use efficiency or plant photosynthetic activity during the entire life cycle of plants. However, Sims and Gamon (2002) and later Filella and collaborators (2009) have already suggested that, as far as the photosynthetic light-use efficiency is correlated with carotenoid/chlorophyll ratio, PRI may still be used as an estimator of RUE during senescence or under stress conditions. It is necessary to note that this relationship may depend upon the operational definition of RUE, i.e. based on incident radiation, total absorbed radiation or radiation absorbed by green vegetation (Gitelson and Gamon, 2015). Additionally, recent researches have advanced in correcting PRI by the effect of seasonal variations in the content of leaf pigments under controlled laboratory conditions (Rahimzadeh-Bajgiran et al., 2012; Hmimina et al., 2013).

\subsection{Relationship between spectral indices}


When data from the A. sativa and S. italica were considered together, stand level PRI did not correlate with stand level NDVI (Table 1). Leaf NDVI did not correlate with stand level NDVI (Table 1). However, if each species was analyzed separately, stand level PRI correlated with stand level NDVI (Pearson's correlation coefficient 0.97, $\mathrm{p}<0.01$ and $0.99, \mathrm{p}<0.05$ for A. sativa and S. italica, respectively). S. italica showed higher values for stand level NDVI than A. sativa. Canopy PRI values were similar during the senescence process in both species (Figure C in SM). The relationship between NDVI and PRI values at stand level for A. sativa was NDVI $=0.97+5.43 *$ PRI, $\mathrm{R}^{2}=0.89, \mathrm{p}<0.04$ and for $S$. italica NDVI $=0.90+1.74 *$ PRI, $\mathrm{R}^{2}=0.99, \mathrm{p}<0.003$

Stylinski et al., (2002) found that canopy PRI did not significantly correlate with canopy NDVI values because they studied evergreen chaparral species. However, in our study both variables were related over the temporal and spatial scales when both species were considered separately. This behavior was expected in two annual grasses as those studied in this work. Although NDVI values for S. italica were higher than those for A. sativa, the first species showed lower values in the chlorophyll content (see Table A in SM). A possible explanation for the observed discrepancy may be the differences in canopy architecture. In fact, A. sativa had thinner leaves and, therefore, more erectophile leaves which produced a more uniform canopy. S. italica, on the other hand, had wider and longer blades resulting in a slight overturning of these leaves and consequently, in a more planophile architecture.

Then, the angle of leaf insertion (leaf inclination) as well as the leaf area index (Haboudane et al., 2004; Jacquemoud et al., 2009) seemed to affect the reflectance spectra of canopies more than the total chlorophyll content. The canopy architecture produced a much greater difference in near infrared which substantially influences the NDVI. In the additional set of data at the canopy level for Cichorium intybus the same effect was observed. The average chlorophyll content of $C$. intybus leaves was $22.00 \pm 1.50 \mathrm{nmol} / \mathrm{cm}^{2}$ of leaf $(\mathrm{n}=6) . S$. 
italica presented similar chlorophyll content in its leaves (at the beginning of senescence). However, the leaves of the first species are erectophile as are the leaves of $A$. sativa. We thought that for these reasons the linear relationship found between NDVI and PRI for $C$. intybus presented a similar slope as that found for A. sativa. The linear regression for $C$. intybus was NDVI $=1.06+7.92 * \mathrm{PRI}, \mathrm{R}^{2}=0.98, \mathrm{p}<0.05$, data not shown. For all these reasons, it seems that the canopy structure, and not the content of pigments, drove the relationship between NDVI and PRI in the grasses evaluated under the conditions of this work.

\subsection{Sun induced fluorescence (SIF) variation between species and ontogeny}

The intensity of sun induced fluorescence extracted from the telluric $\mathrm{O}_{2}$-A absorption band, i.e. $\mathrm{F}_{760}$, as the values of the apparent fluorescence yield at $760 \mathrm{~nm}\left(\mathrm{SIF}_{760} / \mathrm{a}\right)$ were within the range reported for different species (Meroni et al., 2009; Liu and Cheng, 2010; Liu et al., 2013). The apparent fluorescence yield at $760 \mathrm{~nm}$ showed the same global trend in the two studied species (A. sativa and $S$. italica). In A. sativa, $\mathrm{SIF}_{760} /$ a remained approximately constant since the emergence of the first panicle (day 1) until day 22 DFPA, falling systematically afterwards (Figure 4). Even though only three dates were measured for $S$. italica, ,it was possible to observe a slight declining trend in the apparent fluorescence yield (Figure 4). The process of senescence in S. italica was faster than in A. sativa and, for this reason, it was not possible to extend the measures beyond three times in the first case. In both studied species, $\mathrm{SIF}_{760} / \mathrm{a}$ showed a behavior related to the pool of pigment content, which was confirmed by the significant correlation found with PRI (Pearson coefficient $0.88, \mathrm{p}<0.01$ ); but it also related with the structure of the canopy, a fact that was evidenced by the correlation

encountered between PRI and NDVI for each species separately (see section 3.5. Relationship between spectral indices). Therefore, fluorescence signal of canopy followed the behavior of 
two simultaneous effects: the decrease of Total Chlr/Car ratio along time with an increase in the proportion of non-photosynthesizing material occurring at the same time. The signal of fluorescence began to decay on 22 DFPA for A. sativa and so did the stand levels values of PRI and NDVI. On the other hand, in S. italica fluorescence signal fell systematically from the start of measurements as PRI and NDVI values did. In the other set of experiments carried out in canopies of Cichorium intybus and Setaria italica with different proportion of dry material, we could observe the same behavior in the fluorescence signal, i. e. a gradual decrease in this signal when more dried material was incorporated (see figure 5); even when Total Chlr/Car ratio was unchanged in the studied green plants.

\subsection{Kautsky kinetics parameters behaviour between species and ontogeny}

The photosynthetic parameters derived from Kautsky kinetics showed the same trend along time as the apparent fluorescence yield at $760, \mathrm{SIF}_{760} / \mathrm{a}$. For $A$. sativa, they remained approximately constant at the beginning from day 1 to day 31 after first panicle appeared. After this day of measurement, the decrease for $\Phi_{\mathrm{PSII}}$ was greater than for $\mathrm{F}_{\mathrm{v}} / \mathrm{F}_{\mathrm{m}}$ (Figure $\mathrm{C}$ in SM). For S. italica, (although measurements were made only on 3 dates) we could observe that $\Phi_{\mathrm{PSII}}$ values decreased slightly as a function of time while $\mathrm{F}_{\mathrm{v}} / \mathrm{F}_{\mathrm{m}}$ did not show a clear tendency (Inset Figure D, SM). The photosynthetic parameter $\Phi_{\mathrm{PSII}}$, which represents the effective quantum yield of photochemical energy conversion in PSII, resulted a better indicator of disturbances taking place during the natural senescence, than the maximum photochemical efficiency of open reaction centers of PSII $\left(F_{v} / F_{m}\right)$. It was previously reported in literature that $\Phi_{\mathrm{PSII}}$ is a more sensitive parameter than $\mathrm{F}_{\mathrm{v}} / \mathrm{F}_{\mathrm{m}}$ in the presence of stress situations (Iriel et al., 2014; 2015).

Non-photochemical quenching of variable chlorophyll fluorescence was estimated by NPQ, whose values increased after 22 DFPA for A. sativa (Figure E in SM) and from the very 
beginning of the measurements of S. italica (inset on Figure E, SM). The behavior of this parameter through time indicated a higher thermal dissipation at PSII as a consequence of the natural senescence processes. $\mathrm{F}_{\mathrm{v}} / \mathrm{F}_{\mathrm{m}}$ and the non-photochemical parameter did not significantly correlate. Regarding $\Phi_{\mathrm{PSII}}$ and NPQ, both correlated for A. sativa and S. italica but only when they were considered separately (Pearson'́coefficient $=-0.99 p<0.05$, data not shown). This result agreed with Guo and Trotter (2004) who found that decreases in $\Phi_{\text {PSII }}$ among species were generally accompanied by increases in NPQ.

\subsection{Relationship between PRI and fluorescence descriptors (passive and active chlorophyll fluorescence)}

We have found a positive correlation between stand level PRI and the apparent fluorescence yield at $760\left(\mathrm{SIF}_{760} / \mathrm{a}\right)$ also obtained at stand level when data of both species were combined (Pearson coefficient $0.88, \mathrm{p}<0.01$ ), see Table 1 . The same regression model fit the data of both species (Figure 6).

In Figure 7, the apparent fluorescence obtained from the pot assemblies with incorporated dry material as a function of stand level PRI (C. intybus and S. italica) is shown together with those corresponding to the natural senescence of $A$. sativa and $S$. italica.

We found a significant positive correlation between stand level PRI values and the effective quantum yield of PSII ( $\left.\Phi_{\mathrm{PSII}}\right)$ measured at leaf level when data of both species were combined (Pearson coefficient 0.82, $\mathrm{p}<0.05$ ) (Table 1 and Figure 8). No significant correlations were found between PRI and the maximum quantum yield of PSII $\left(\mathrm{F}_{\mathrm{v}} / \mathrm{F}_{\mathrm{m}}\right)($ Table 1$)$.

As others have shown (Guo and Trotter, 2004; Filella et al., 2009; Weng et al., 2006; 2010), we found a strong correlation between PRI values obtained at leaf level with $F_{v} / F_{m}$ and $\Phi_{\text {PSII }}$ in our results when data of both species were considered together (Pearson' correlation 
coefficient: 0.71 and 0.69 , respectively, both $\mathrm{p}<0.05$ ) (Table 1). When we included in the analysis data from leaves of other species at different stages of senescence (Paspalum dilatatum, Dactylis glomerata, Brassica napus L, Liquidambar styraciflua and Rhus sylvestris), we also found a significant correlations between leaf PRI and the two photochemical parameters considered, Fv/Fm $=0.76+1.46 * \mathrm{PRI}, \mathrm{R}^{2}=0.76, \mathrm{p}<0.05 ; \Phi_{\mathrm{PSII}}=$ $0.64+1.65 *$ PRI, $\mathrm{R}^{2}=0.78, \mathrm{p}<0.05$ (Figures $\mathrm{F}$ and $\mathrm{G}$ in the SM, respectively).

As mentioned before, NPQ can provide valuable information about the non-radiative deactivation pathway. There was no single correlation between PRI and NPQ when both species were considered together (Figure 9). In A. sativa higher values of thermal dissipation were reached at the end of senescence. On the other hand, even though we only performed measurements on three dates in S. italica, the values obtained for NPQ never overcame the value of 0.3 . The metabolic pathway of the studied species may explain the observed differences. In fact, Setaria italica, a C4 species, has lower photoprotection requirements, as it shows higher tolerance to conditions of high irradiance and heat and water deficiency. Accordingly, low values for the non photochemical quenching parameters are expected for this species. On the other hand, Avena sativa is a C3 species with lower resistance to extreme conditions, presenting a high need of photoprotection and, accordingly, greater values of NPQ. Similar observations were made earlier by Brugnoli and colleagues in sun and shade leaves of C3 and C4 plants (Brugnoli et al., 1998). More recent works confirmed these results, Guo and Trotter (2004) found that decreases in $\Phi_{\mathrm{PSII}}$ among species were generally accompanied by increases in NPQ and broadly associated with decreases in PRI. Nichol and collaborators (2006) in a dense experimental mangrove canopy found similar results.

The correlation between $\mathrm{SIF}_{760} / \mathrm{a}$ with PRI was higher than correlations between PRI and the photosynthetical parameters ( $\Phi_{\mathrm{PSII}}$ and NPQ). So, PRI would be a good proxy of $\mathrm{SIF}_{760} / \mathrm{a}$. Previous articles have reported positive relationships between PRI and RUE in 
herbaceous at leaf(Gamon et al., 1997; Guo and Trotter, 2004) and canopy (Strachan et al., 2002; Cheng et al., 2013) scales (Garbulsky et al., 2011). Based on these results and ours (Figure 8), we assume that increases in the values of PRI (less negative values) and in the effective quantum yield of PSII ( $\left.\Phi_{\mathrm{PSII}}\right)$ would indicate greater values of RUE.

Regarding the apparent sun-induced fluorescence yield at $760 \mathrm{~nm}\left(\mathrm{SIF}_{760} / \mathrm{a}\right)$, it should be inversely related to RUE but only if non-photochemical quenching remains constant. Liu and Cheng confirmed this behavior in wheat and maize at leaf and canopy levels (Liu and Cheng, 2010). However, in our work the values of NPQ increased over time (Figure E in SM). In a recent review, the authors argue that SIF and quantum yield of photochemistry in PSII vary concomitantly in response to stress under high-light conditions (measurements carried out during the midday as in our work) (Porcar-Castell et al., 2014). This behavior is explained in that changes in quantum yield of photochemistry of PSII are dominated by the nonphotochemical quenching, whilst the photochemical quenching remained constant (PorcarCastell et al., 2014). As mentioned before, we observed increases in NPQ values along time in both studied species while the Photochemical Quenching Coefficient (qP), a parameter calculated as $\left(\mathrm{F}_{\mathrm{m}}^{\prime}-\mathrm{F}_{\mathrm{s}}\right) /\left(\mathrm{F}_{\mathrm{m}}^{\prime}-\mathrm{F}_{0}\right)($ Lagorio, 2011) and related with photochemical quenching, remained close to 1 in both cases (data not shown). For all these reasons, under our conditions of measurements, we would expect a positive correlation between $\mathrm{SIF}_{760} / \mathrm{a}$ and $\Phi_{\mathrm{PSII}}$ and hence with RUE.

\subsection{Relationship between active and passive chlorophyll fluorescence parameters.}

Photosynthetic parameters derived from Kautsky kinetics (active fluorescence) obtained at leaf level correlated with apparent sun induced fluorescence yield (passive fluorescence) obtained at stand level (Table 1). The best correlation was found between $\mathrm{SIF}_{760} / \mathrm{a}$ and $\Phi_{\mathrm{PSII}}$ (Pearson coefficient: $0.89 \mathrm{p}<0.01$ ). These two parameters showed the behavior in steady 
state conditions with plants adapted to ambient light. In a very comprehensive review PorcarCastell et al. (2014) argued that fluorescence yield was related to photochemical yield and hence to RUE.

The NPQ, instead, did not correlate with apparent sun induced fluorescence yield. Working with Trifolium repens $L$. exposed to the action of ozone (chlorophyll degradation connected to senescence-like mechanisms have been reported as a common effect of ozone exposure) Meroni et al (2008) found that in the early phase of stress, SIF at $760 \mathrm{~nm}$ decreased significantly in treated plants with respect to controls after 1 day of treatments. At the same time, plants showed a significant decrease in $\Phi_{\mathrm{PSII}}$ from day 4 on fumigation with ozone. A significant decrease in $\mathrm{F}_{\mathrm{v}} / \mathrm{F}_{\mathrm{m}}$ was experienced by treated plants after 21 days of fumigation (Meroni et al., 2008).

It should be noticed that the results of this section are strictly valid for the experimental set up used in this work. In fact, Julitta et al., (2016) recently pointed out in their detailed and exhaustive comparison of four commercial field spectroradiometers that different devices yielded diverse absolute values for the retrieved fluorescence in the red and in the far-red. This fact, however, does not invalidate the usefulness of the measured SIF/a as a proxy of photosynthetic RUE, given the high Pearson's correlation coefficient found here between SIF/a and $\Phi_{\text {PSII }}$ (Pearson coefficient: 0.89 in Table 1). The parameter $\Phi_{\text {PSII }}$ (measured in this work under the same light conditions as SIF) is one of the most widely accepted fluorescence parameters related to the physiological state of a plant (Maxwell and Johnson, 2000).

\section{Conclusions}

Our results showed that two chlorophyll fluorescence signals $\Phi_{\mathrm{PSII}}$ and the apparent suninduced fluorescence yield at $760 \mathrm{~nm}\left(\mathrm{SIF}_{760} / \mathrm{a}\right)$ correlated with the canopy PRI values in the two grasses assessed along senescence. This correlation may be explained in conjunction with 
the decrease of chlorophyll content along senescence. In fact, during the natural aging process, the photosynthetic activity diminished (decrease in Fv/Fm and $\Phi_{\mathrm{PSII}}$ ), the chlorophyll content decreased and consequently its fluorescence also dropped. Even when significant changes occurred in the Total Chlr/Car ratio along senescence in both studied species, the correlation observed between PRI and the chlorophyll fluorescence parameters might indicate the usefulness of this reflectance index as a proxy of photosynthetic RUE. The relationships found between stand level PRI values and the fluorescence estimators $\left(\Phi_{\mathrm{PSII}}\right.$ and $\left.\mathrm{SIF}_{760} / \mathrm{a}\right)$ were positive and linear in both cases. These results, together with those obtained in previous works, would indicate lower values of RUE when PRI or fluorescence estimators decreased under stress conditions. In this case, the PRI values became more negative.

The use of a modulated fluorometer allows a rapid measurement of the $\Phi_{\mathrm{PSII}}$. However, these determinations are restricted to the leaf level. $\mathrm{SIF}_{760} / \mathrm{a}$ has the additional advantage of allowing proximal sensing of the photosynthetic activity of the whole canopy by means of a portable spectroradiometer. Our experiments were carried out throughout the process of natural senescence for the two studied species, showing that the relationships found applied not only to healthy vegetation (as already proposed by some authors) but also to senescent plants or under stress conditions. These results were supported by experiments conducted also at stand level where we modified artificially the proportion of dry matter content of canopy.

A noteworthy result derived from the present study was the fact that significant linear correlations between leaf PRI and photosynthetical parameters as $\mathrm{F}_{\mathrm{v}} / \mathrm{F}_{\mathrm{m}}$ and $\Phi_{\mathrm{PSII}}$, the latter derived from chlorophyll fluorescence, were obtained from leaves of different plant species considered together (Setaria italica, Avena sativa, Paspalum dilatatum, Dactylis glomerata, Brassica napus L, Liquidambar styraciflua and Rhus sylvestris). The independence of this correlation of the type of species considered, suggested a sort of generality that, although it 
should be verified for additional species, resulted very promising for the remote monitoring of RUE. In fact, this work showed that measuring leaf PRI along senescence may give information about the physiological state of the plant. Furthermore, leaf PRI would allow comparison of plant health of different species in diverse ontogenic states. The strong correlation found in this work as in previous studies between leaf and stand level PRI points in the same direction. The positive correlation among PRI, Fv/Fm and $\Phi_{\mathrm{PSII}}$ may be easily rationalized in terms of an increase in the reflectance at $570 \mathrm{~nm}$, due to chlorophyll losses (reduction in PRI value) as leaf senesces and drops its photosynthetic activity (decrease in Fv/Fm and $\left.\Phi_{\text {PSII }}\right)$. Moreover, Total Chl/Car ratio correlated with Fv/Fm and $\Phi_{\text {PSII }}$ because during the senescence process the decrease in photochemical activity was accompanied by a diminution of total chlorophyll while carotenoids increased. Although the results presented here should be verified for additional species, this work represents a promising starting point.

We found that (1) Total Chlr/Car ratio was the best pigment indicator of senescence in both grasses species. (2) Stand level NDVI patterns were related to changes in the structure of canopies and not to the pigment content. (3) Stand level PRI patterns suggested changes both in terms of the structure of canopies and the pigment content of leaves. (4) NDVI and PRI values at stand level highly correlated for each species separately due to differences in the structures of both canopies. Accompanying these effects,(5) a decrease in the apparent suninduced fluorescence yield at $760 \mathrm{~nm}$ and $\Phi_{\mathrm{PSII}}$ was noticed. A strong increment in NPQ was evidenced in Avena sativa, a C3 species, which has lower resistance to extreme conditions and, therefore, higher requirements of photoprotection. While in Setaria italica, a C4 species, NPQ values were lower than in the other grass in accordance with its higher tolerance to extreme environmental conditions. (6) The high significant correlation between $\mathrm{SIF}_{760} / \mathrm{a}$ and PRI would indicate that fluorescence signal was affected simultaneously by the two factors affecting PRI, Total Chlr/Car ratio and changes in the structure of canopies. 
Beyond the temporal dynamics, the underlying reason supporting the high correlation between stand-level PRI and leaf PRI is the use of homogenous canopies that may be considered as a big leaf. Remarkably, it was shown here that the optical properties of the canopy may be described by the optical properties of individual leaves even when senescent material is present.

\section{Acknowledgments}

The authors are grateful to the University of Buenos Aires (UBACyT 20020100100814, 20020130100166BA, and UBACyT 20020100100835) and to the Agencia Nacional de Promoción Científica y Tecnológica (PICT 2012-2357, PICT 2008-2199 and PICT-20131785) for the financial support. This work was partially funded on the INIA-FPTA 305 project and on agreement between the Facultad de Ciencias (UDELAR) and the Ministerio de Ganadería, Agricultura y Pesca (Uruguay). This work was carried out with the aid of a grant from the Inter-American Institute for Global Change Research (IAI) CRN3095 which is supported by the US National Science Foundation (Grant GEO-1128040). JMP, MGL and GBC are researcher scientists from CONICET. We also thank Mayra Milkovic for her assistance during measurements.

\section{References}

Asner GP. Biophysical and biochemical sources of variability in canopy reflectance. Remote Sens Environ 1998; 64: 234-53.

Barton CVM, North PRJ. Remote sensing of canopy light use efficiency using the photochemical reflectance index. Model and sensitivity analysis. Remote Sens Environ 2001; 78: 264-73. 
Brugnoli E, Scartazza A, De Tullio MC, Monteverdi MC, Lauteri M, Augusti A. Zeaxanthin and non-photochemical quenching in sun and shade leaves of C3 and C4 plants. Physiol Plant 1998; 104: 727-34.

Cheng YB, Middleton E, Zhang Q, Huemmrich K, Campbell P, Corp L et al. Integrating solar induced fluorescence and the photochemical reflectance index for estimating gross primary production in a cornfield. Remote Sens 2013; 5: 6857-79.

Cordon GB, Lagorio MG. Optical properties of the adaxial and abaxial faces of leaves. Chlorophyll fluorescence, absorption and scattering coefficients. Photochem Photobiol Sci 2007; 6: 873-82.

Damm A, Elbers J, Erler A, Gioli B, Hamdi K, Hutjes R et al. Remote sensing of suninduced fluorescence to improve modeling of diurnal courses of gross primary production (GPP). Glob Change Biol 2010; 16: 171-86.

Daughtry CST, Biehl LL, Ranson K. J. A new technique to measure the spectral properties of conifer needles. Remote Sens Environ 1989; 27: 81-91.

Demmig B, Winter K, Krüger A, Czygan FC. Photoinhibition and zeaxanthin formation in intact leaves: A possible role of the xanthophyll cycle in the dissipation of excess light energy. Plant Physiol 1987; 84: 218-24.

Demmig-Adams B, Adams WW. The role of xanthophyll cycle carotenoids in the protection of photosynthesis. Trends Plant Sci 1996; 1: 21-6.

Di Bella CM, Paruelo JM, Becerra JE, Bacour C, Baret F. Experimental and simulated evidences of the effect of senescent biomass on the estimation of $f_{\mathrm{PAR}}$ from NDVI measurements on grass canopies. Int J Remote Sens 2004; 25: 5415-27.

Di Rienzo JA, Casanoves F, Balzarini MG, Gonzalez L, Tablada M, Robledo CW. InfoStat Versión 2010, Grupo InfoStat, FCA, Universidad Nacional de Córdoba, Córdoba, Argentina, http://www.infostat.com.ar/ 
Field CB. Ecological scaling of carbon gain to stress and resource availability. In: Mooney HA, Winner WE, Pell EJ, editors. Integrated Responses of Plants to Stress. New York: Academic Press, 1991. p 1-32.

Filella I, Porcar-Castell A, Munné-Bosch S, Bäck J, Garbulsky MF, Peñuelas J. PRI assessment of long-term changes in carotenoids/chlorophyll ratio and short-term changes in de-epoxidation state of the xanthophyll cycle. Int J Remote Sens 2009; 30: 4443-55.

Gamon J, Peñuelas J, Field C. A narrow-waveband spectral index that tracks diurnal changes in photosynthetic efficiency. Remote Sens Environ 1992; 41: 35-44.

Gamon J, Serrano L, Surfus J, The photochemical reflectance index: an optical indicator of photosynthetic radiation use efficiency across species, functional types, and nutrient levels. Oecologia 1997; 112: 492-501.

Gamon J, Field C, Fredeen A, Thayer S. Assessing photosynthetic downregulation in sunflower stands with an optically-based model. Photosynth Res 2001; 67: 113-25.

Gamon J, Bond B. Effects of irradiance and photosynthetic downregulation on the photochemical reflectance index in Douglas-fir and ponderosa pine. Remote Sens Environ 2013; 135: 141-49.

Gamon J, Kovalchuk O, Wong C, Harris A, Garrity S. Monitoring seasonal and diurnal changes in photosynthetic pigments with automated PRI and NDVI sensors. Biogeosciences Discuss 2015; 12: 2947-78.

Garbulsky M, Peñuelas J, Gamon J, Inoue Y, Filella I. The photochemical reflectance index (PRI) and the remote sensing of leaf, canopy and ecosystem radiation use efficiencies. A review and meta-analysis. Remote Sens Environ 2011; 115: 281-97.

Gilmanov TG, Tieszen LL, Wylie BK, Flanagan LB, Frank AB, Haferkamp MR et al. Integration of $\mathrm{CO}_{2}$ flux and remotely sensed data for primary production and ecosystem 
respiration analyses in the Northern Great Plains: potential for quantitative spatial extrapolation. Global Ecol Biogeogr 2005; 14: 271-92.

Gitelson A, Gamon J. The need for a common basis for defining light-use efficiency: Implications for productivity estimation. Remote Sens Environ 2015; 156: 196-201.

Grace J, Nichol C, Disney M, Lewis P, Quaife T, Bowyer P. Can we measure terrestrial photosynthesis from space directly, using spectral reflectance and fluorescence? Glob Change Biol 2007; 13: 1484-97.

Grigera G, Oesterheld M, Pacin F. Monitoring forage production for farmer's decision making. Agr Syst 2007; 94: 637-48.

Guanter L, Alonso L, Gomez-Chova L, Meroni M, Preusker R, Fischerand J et al. Developments for vegetation fluorescence retrieval from spaceborne high-resolution spectrometry in the $\mathrm{O}_{2}-\mathrm{A}$ and $\mathrm{O}_{2}-\mathrm{B}$ absorption bands. J Geophys Res-Atmos 2010, 115: D19

Guo J, Trotter C. Estimating photosynthetic light-use efficiency using the photochemical reflectance index: variations among species. Funct Plant Biol 2004; 31: 25565.

Haboudane D, Miller J, Pattey E, Zarco-Tejada P, Strachan I. Hyperspectral vegetation indices and novel algorithms for predicting green LAI of crop canopies: Modeling and validation in the context of precision agriculture. Remote Sens Environ 2004; 90: 337-52.

Hall AJ, Connor DJ, Sadras VO. Radiation-use efficiency of sunflower crops: effects of specific leaf nitrogen and ontogeny. Field Crop Res 1995; 41: 65-77.

Hilker T, Coops NC, Wulder MA, Black TA, Guy RD. The use of remote sensing in light use efficiency based models of gross primary production: A review of current status and future requirements. Sci Total Environ 2008; 404: 411-23.

Hmimina G, Dufrêne E, Soudani K. Relationship between photochemical reflectance index and leaf ecophysiological and biochemical parameters under two different water 
statuses: towards a rapid and efficient correction method using real-time measurements. Plant Cell Environ 2013; 37: 473-87.

Hoagland DR, Arnon DI. The water culture method for growing plants without soil. Calif Agr Expt Sta Circ 1950; 347: 1-32.

Iriel A, Novo J, Cordon G, Lagorio MG. Atrazine and methyl viologen effects on chlorophyll-a fluorescence, revisited-implications in photosystems emission and ecotoxicity assessment. Photochem Photobiol 2014; 90: 107-12.

Iriel A, Dundas G, Fernández Cirelli A, Lagorio MG. Effect of arsenic on reflectance spectra and chlorophyll fluorescence of aquatic plants. Chemosphere 2015; 119: 697-703. Jacquemoud S, Verhoef W, Baret F, Bacour C, Zarco-Tejada PJ, Asner GP et al. PROSPECT + SAIL: a review of use for vegetation characterization. Remote Sens Environ 2009; 113: S56-S66.

Julitta T, Corp L, Rossini M, Burkart A, Cogliati S, Davies N et al. Comparison of sun-induced chlorophyll fluorescence estimates obtained from four portable field spectroradiometers. Remote Sens 2016, 8: 122; doi:10.3390/rs8020122.

Lagorio MG. Chlorophyll fluorescence emission spectra in photosynthetic organisms. In: Le H, Salcedo E, editors. Chlorophyll: Structure, Production and Medicinal Uses. Hauppauge NY: Nova publisher, 2011, p 115-50.

Lichtenthaler HK, Buschmann C. Chlorophylls and carotenoids: measurement and characterization by UV-VIS spectroscopy. In: Wrolstad RE, Acree TE, An H, Decker EA, Penner MH, Reid DS et al., editors. Current Protocols in Food Analytical Chemistry. New York: Wiley and Sons, 2001. F4.3.1-F4.3.8.

Liu L, Cheng Z. Detection of vegetation light-use efficiency based on solar-induced chlorophyll fluorescence separated from canopy radiance spectrum. IEEE J Sel Topics Appl Earth Observ in Remote Sens 2010; 3: 306-12. 
Liu L, Zhao J, Guan L. Tracking photosynthetic injury of paraquat-treated crop using chlorophyll fluorescence from hyperspectral data. Eur J Remote Sens 2013; 46: 459-473.

Louis J, Ounis A, Ducruet JM, Evain S, Laurila T, Thum T et al. Remote sensing of sunlight-induced chlorophyll fluorescence and reflectance of scots pine in the boreal forest during spring recovery. Remote Sens Environ 2005; 96: 37-48.

Malenovský Z, Mishra K, Zemek F, Rascher U, Nedbal L. Scientific and technical challenges in remote sensing of plant canopy reflectance and fluorescence. J Exp Bot 2009; 60: $2987-3004$.

Martínez AC, Paruelo JM, Alcaraz-Segura D, Cabello J, Oyarzabal M, LópezCarrique E. Missing gaps in the estimation of the carbon gains service from light use efficiency models. In: Alcaraz-Segura D, Di Bella C, Straschnoy J, editors. Earth observations of ecosystems services. New York: CRC Press - Taylor and Francis Group, 2013. p 105-24.

Maxwell K, Johnson G. Chlorophyll fluorescence- A practical guide. J Exp Bot 2000; 51: $659-68$.

McNaughton SJ, Oesterheld M, Frank DA, Williams KJ. Ecosystem-level patterns of primary productivity and herbivory in terrestrial habitats. Nature 1989; 341: 142-44.

Meroni M, Rossini M, Picchi V, Panigada C, Cogliati C, Colombo R. Assesing steadystate fluorescence and PRI from hyperspectral proximal sensing as early indicators of plants stress: The case of ozone exposure. Sensor 2008; 8: 1740-54.

Meroni M, Rossini M, Guanter L, Alonso L, Rascher U, Colombo R et al. Remote sensing of solar-induced chlorophyll fluorescence: Review of methods and applications. Remote Sens Environ 2009; 113: 2037-51.

Monteith JL. Solar radiation and productivity in tropical ecosystems. J Appl Ecol 1972; 9: 747-66. 
Monteith JL. Climate and the efficiency of crop production in Britain (and discussion). Philos Trans R Soc Lond B Biol Sci 1977; 281: 277-94.

Moya I, Camenen L, Evain S, Goulas Y, Cerovic Z, Latouche G et al. A new instrument for passive remote sensing: 1. Measurements of sunlight-induced chlorophyll fluorescence. Remote Sens Environ 2004; 91: 186-97.

Nichol C, Rascher U, Matsubara S, Osmond C. Assessing photosynthetic efficiency in an experimental mangrove canopy using optical remote sensing and chlorophyll fluorescence. Trees 2006; 20: 9-15.

Oyarzabal M, Oesterheld M, Grigera G. ¿Cómo estimar la eficiencia en el uso de la radiación mediante sensores remotos y cosechas de biomasa? In: Altesor A, Ayala W, Paruelo JM, editors. Bases ecológicas y tecnológicas para el manejo de pastizales. Montevideo: Unidad de Comunicación y Transferencia de Tecnología del INIA, 2010. p 119-31.

Pedrós R, Goulas Y, Jacquemound S, Louis J, Moya I. FluorMODleaf: A new leaf fluorescence emission model based on the PROSPECT model. Remote Sens Environ 2010; 114: $155-67$.

Peñuelas J, Filella I, Gamon J. Assessment of photosynthetic radiation use efficiency with spectral reflectance. New Phytol 1995; 131: 291-96.

Piñeiro G, Oesterheld M, Paruelo JM. Seasonal variation in aboveground production and radiation use efficiency of temperate rangelands estimated through remote sensing. Ecosystems 2006; 9: 357-73.

Porcar-Castell A, Tyystjärvi E, Atherton J, van der Tol C, Flexas J, Pfündel EE et al. Linking chlorophyll a fluorescence to photosynthesis for remote sensing applications: mechanisms and challenges. J Exp Bot 2014; 65: 4065-95. 
Rahimzadeh-Bajgiran P, Munehiro M, Omasa K. Relationships between the photochemical reflectance index (PRI) and chlorophyll fluorescence parameters and plant pigment indices at different leaf growth stages. Photosynth Res 2012; 113: 261-71.

Rosenqvist E, van Kooten O. Chlorophyll fluorescence: a general description and nomenclature. In: De Ell JR, Toivonen PMA, editors. Practical Applications of Chlorophyll Fluorescence in Plant Biology. Boston: Kluwer Academic Publishers, 2003. p 31-78.

Running SW, Thornton PE, Nemani RR, Glassy JM. Global terrestrial gross and net primary productivity from the earth observing system. In: Sala O, Jackson R, Mooney H, editors. Methods in Ecosystem Science, New York: Springer-Verlag, 2000. p 44-57.

Schurr U, Walter A, Rascher U. Functional dynamics of plant growth and photosynthesis - from steady-state to dynamics - from homogeneity to heterogeneity. Plant Cell Environ 2006; 29: 340-52.

Sellers PJ, Berry JA, Collatz GJ, Field CB, Hall FG. Canopy reflectance, photosynthesis, and transpiration.III. A reanalysis using improved leaf models and a new canopy integration scheme. Remote Sens Environ 1992; 42: 187-216.

Sims D, Gamon J. Relationships between leaf pigment content and spectral reflectance across a wide range of species, leaf structures and developmental stages. Remote Sens Environ 2002; 81: 337-54.

Soudani K, Hmimina G, Dufrêne E, Berveiller D, Delpierre N, Ourcival J-M et al. Relationships between photochemical reflectance index and light-use efficiency in deciduous and evergreen broadleaf forests. Remote Sens Environ 2014; 144: 73-84.

Strachan IB, Pattey E, Boisvert J. B. Impact of nitrogen and environmental conditions on corn as detected by hyperspectral reflectance. Remote Sens Environ 2002; 80: 213-24.

Stylinski C, Gamon J, Oechel W. Seasonal patterns of reflectance indices, carotenoid pigments and photsynthesis of evergreen chaparral species. Oecologia 2002; 131: 366-74. 
Tambussi E, Casadesus J, Munné-Bosch S, Araus JL. Photoprotection in waterstressed plants of durum wheat (Triticum turgidum var. durum): changes in chlorophyll fluorescence, spectral signature and photosynthetic pigments. Funct Plant Biol 2002; 29: 3544.

Trotter C, Whitehead D, Pinkney E. The photochemical reflectance index as a measure of photosynthetic light use efficiency for plants with varying foliar nitrogen constraints. Int $\mathbf{J}$ Remote Sens 2002; 23: 1207-12.

Weng JH, Liao TS, Hwang MY, Chung ChCh, Lin CP, Chu ChH. Seasonal variation in photosystem II efficiency and photochemical reflectance index of evergreen trees and perennial grasses growing at low and high elevations in subtropical Taiwan. Tree Physiol 2006; 26: 1097-104.

Spectral Calculator Spreadsheets, http://brucelindbloom.com/, (accessed November 2015). 
Days after first panicle appeared (DFPA) in Avena sativa

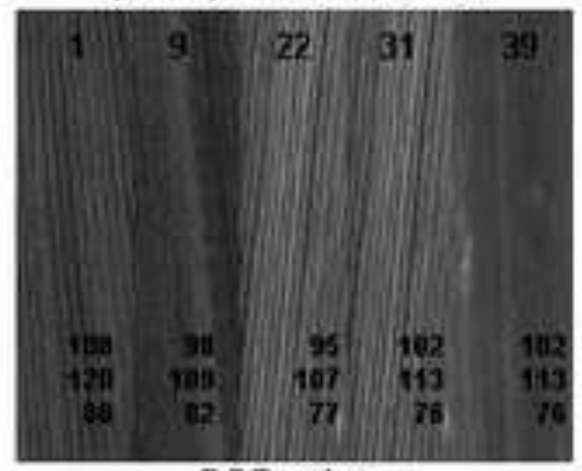

RGB values
Days after first panicle appeared (DFPA) in Setaris italica

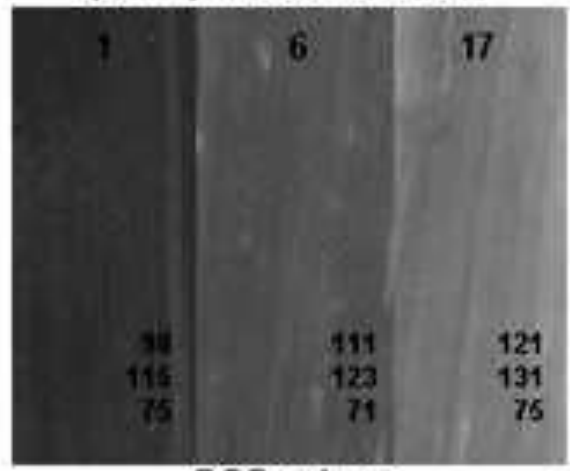

RGB values

Figure 1. Photographs show representative leaves at each day of measurement in both studied species: Avena sativa (left) and Setaria italica (right). Numbers on top of photographs represent the days after first panicle appeared (DFPA). In both cases measurements began when the first panicle became evident (day 1). In the lower part of each photograph the RGB values were added (average of ten measurements). 


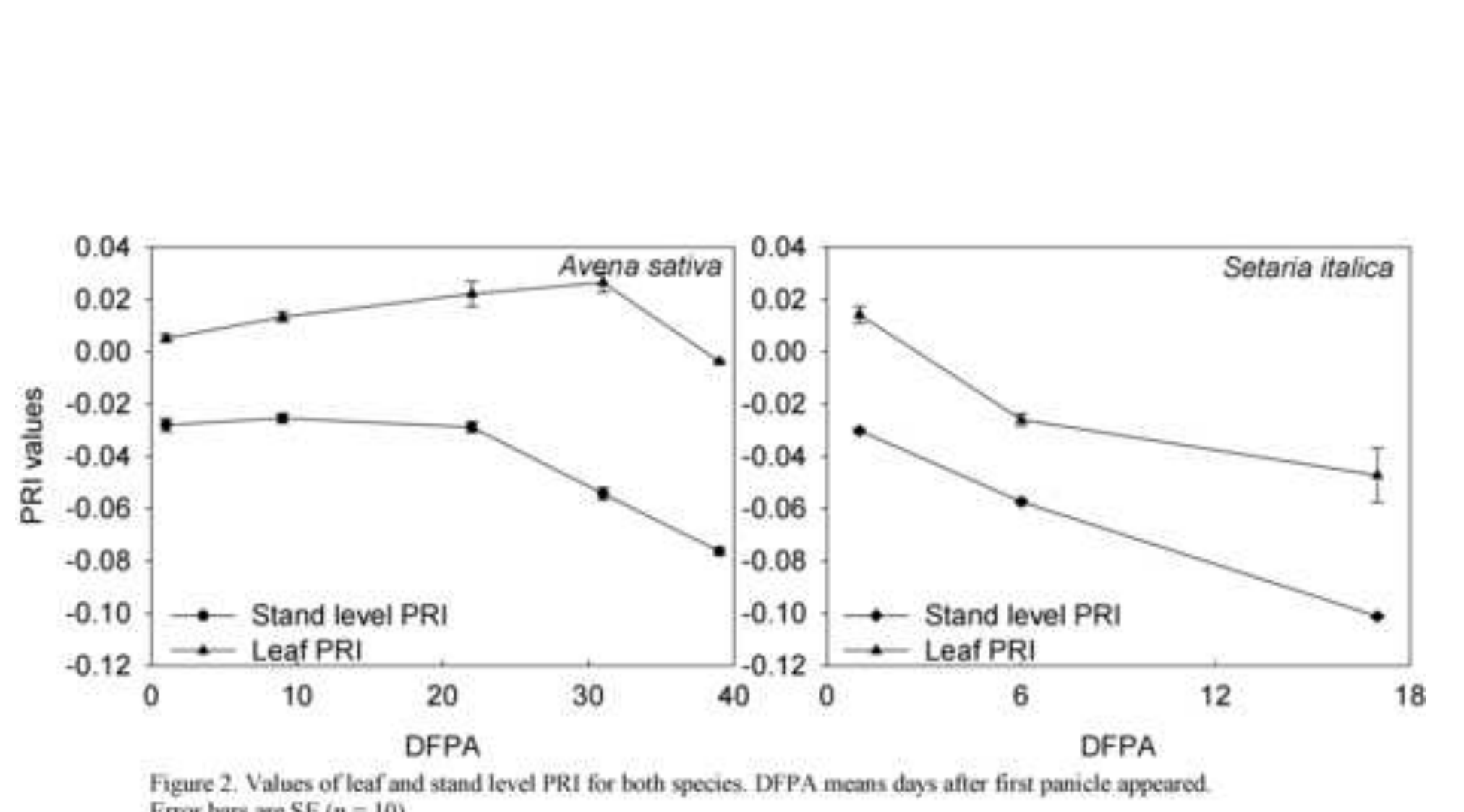

Figure 2. Values of leaf and stand level PRI for both species. DFPA means days affer first panicle appeared. Error bars are $\mathrm{SE}(\mathrm{n}=10)$.

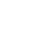

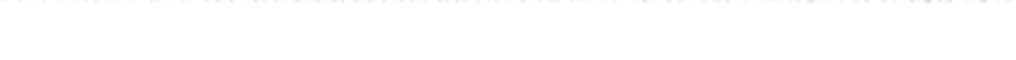

(2)

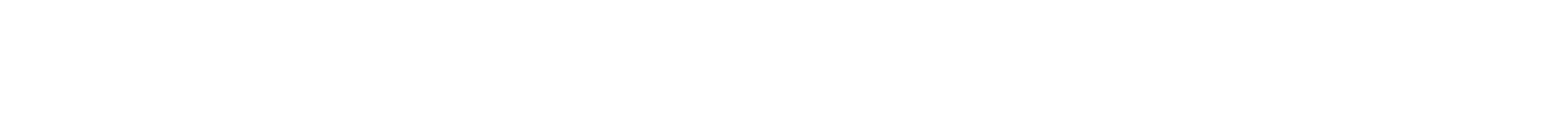

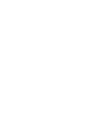

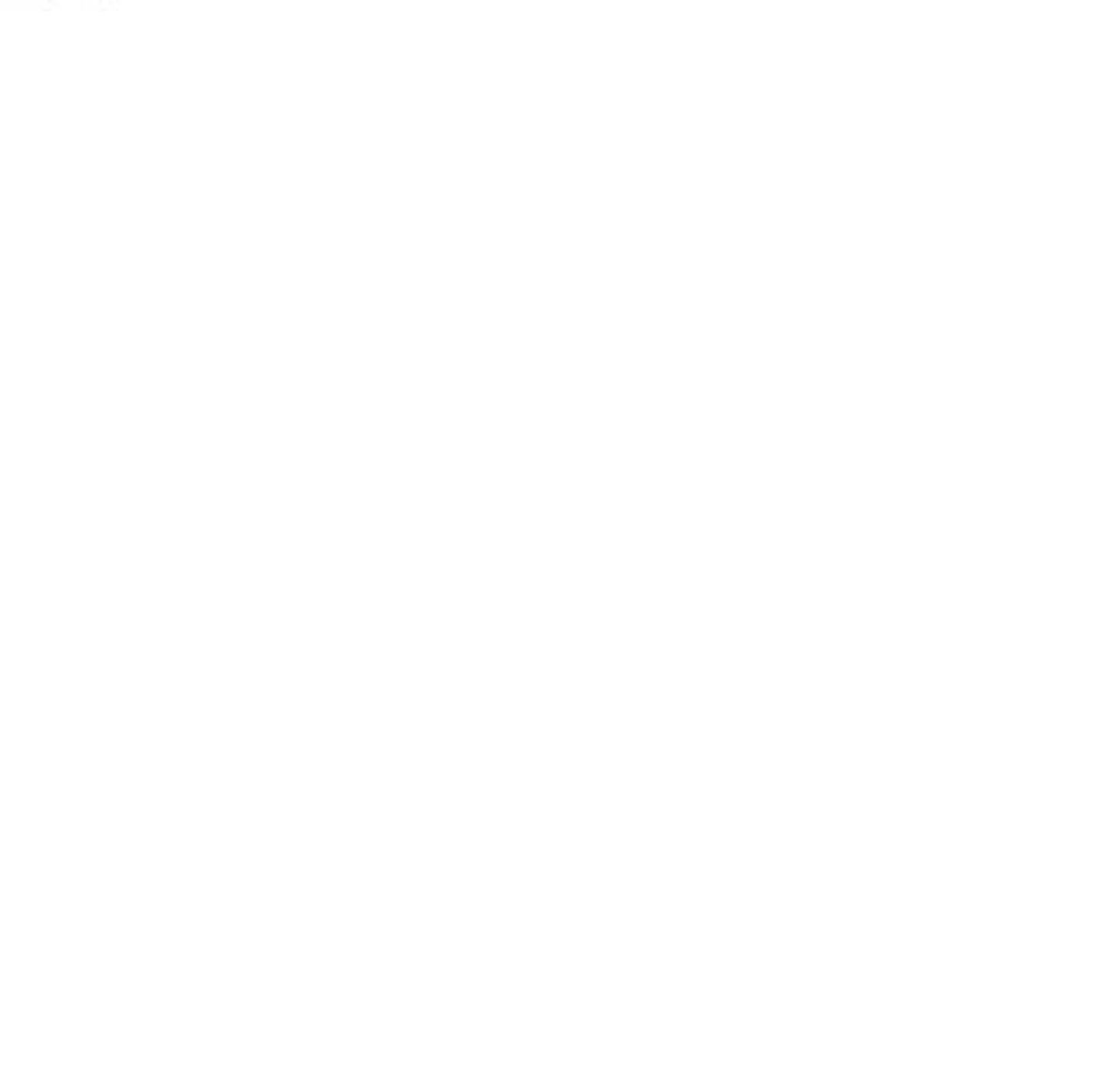



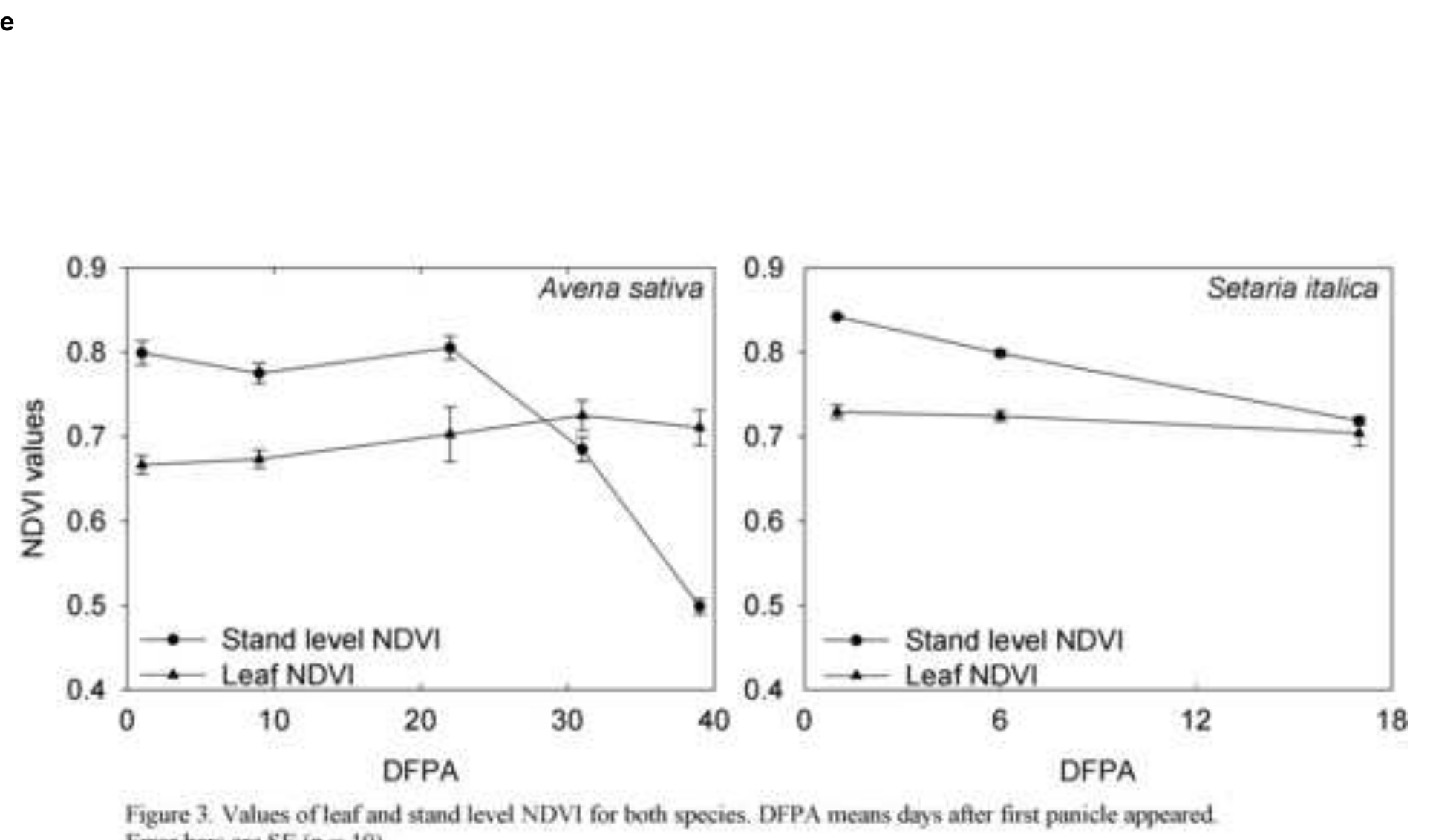

Figure 3. Values of leaf and stand level NDVI for both species. DFPA means days after first panicle appeared.
Error bars are $\mathrm{SE}(\mathrm{n}=10)$. Error bars are $S E(a=10)$.

d stand level NDVT for both species. DFPA means days after first punicle ap

8

Cor

\section{Figure}

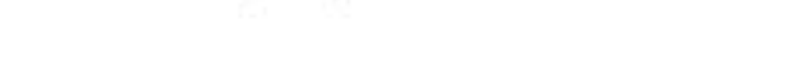

DFPA 

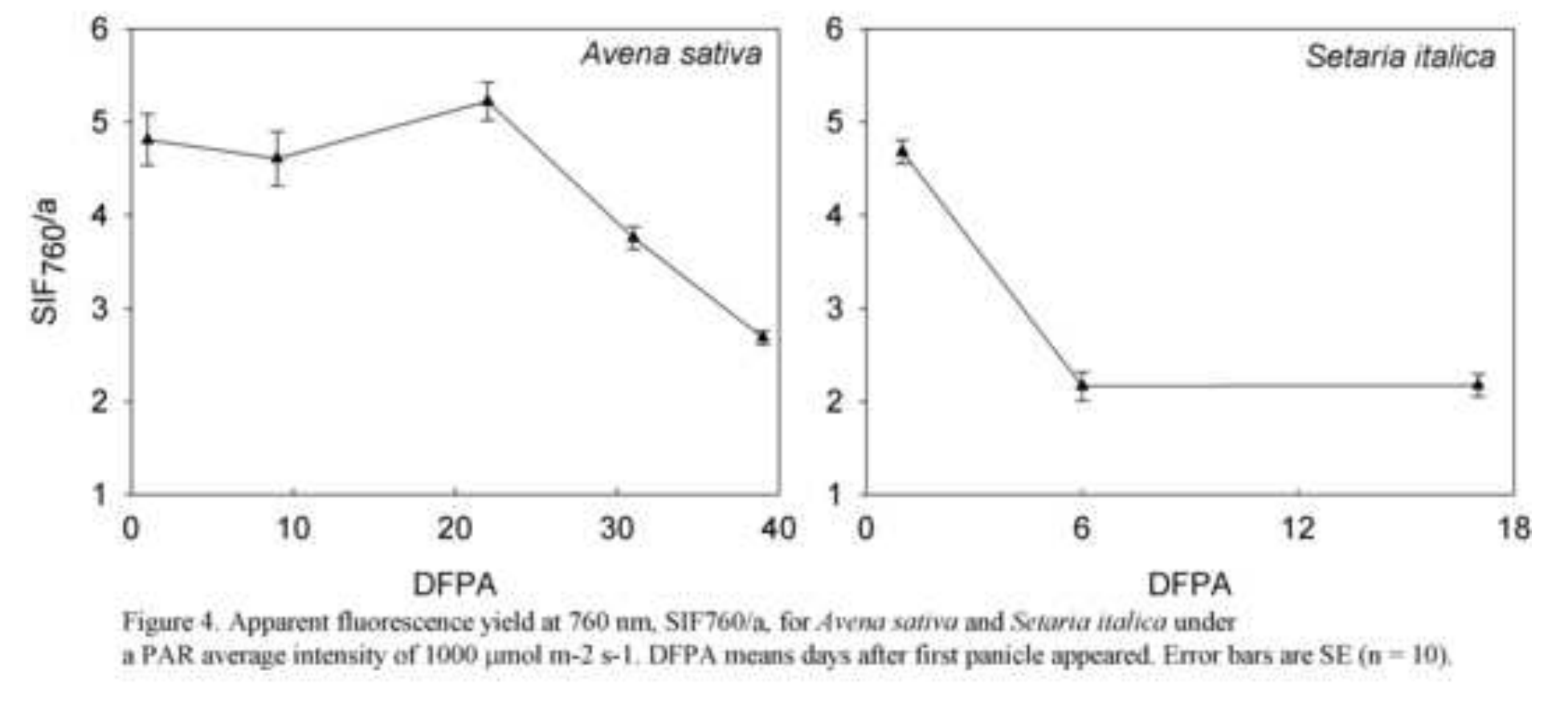

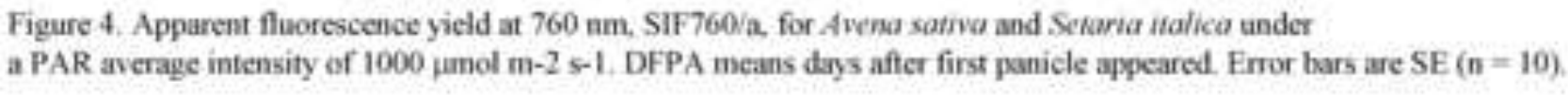

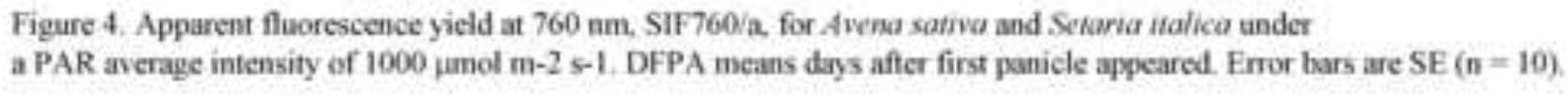

8

\section{Figure}

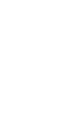

(1)

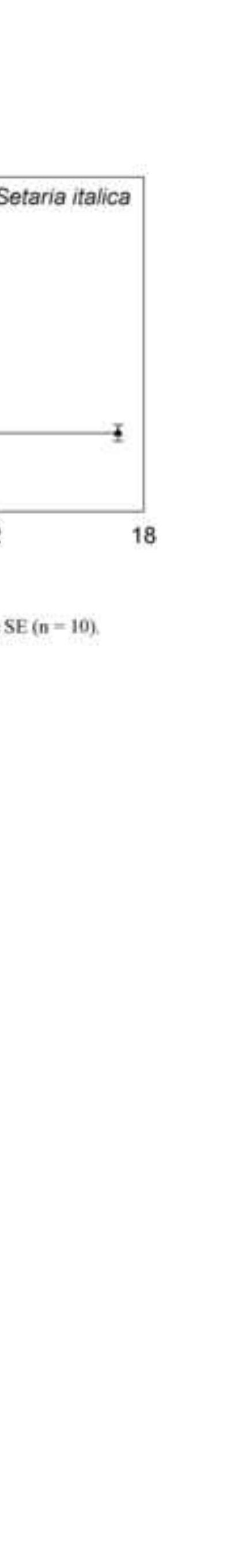



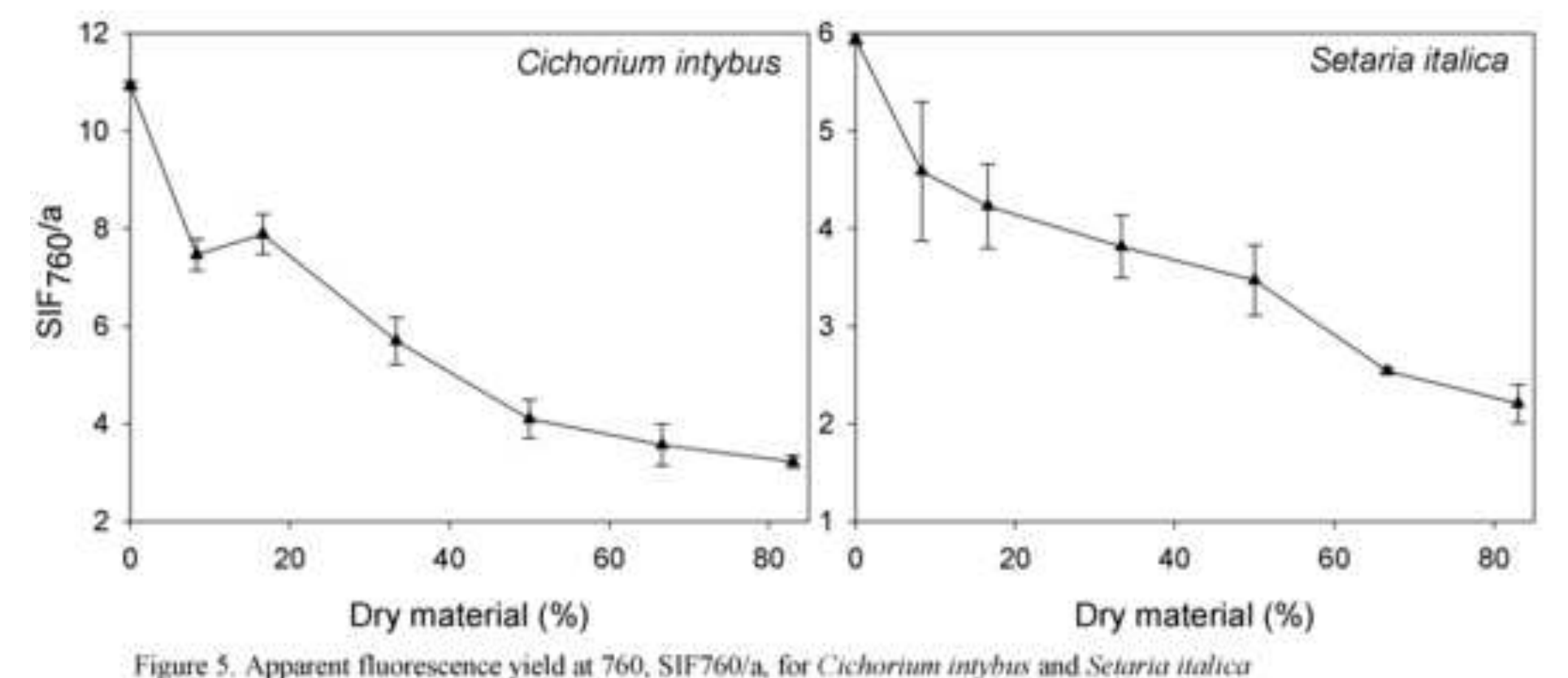

Figure 5. Apparent flaorescence yield at 760, SIF760/a, for Cichoriam intybas and Sekaria inalica under a PAR average intensity of $1000 \mu \mathrm{mol} m-2 \mathrm{~s}-1$. Error bars are $\mathrm{SE}(\mathrm{n}-5)$.

Eigure 


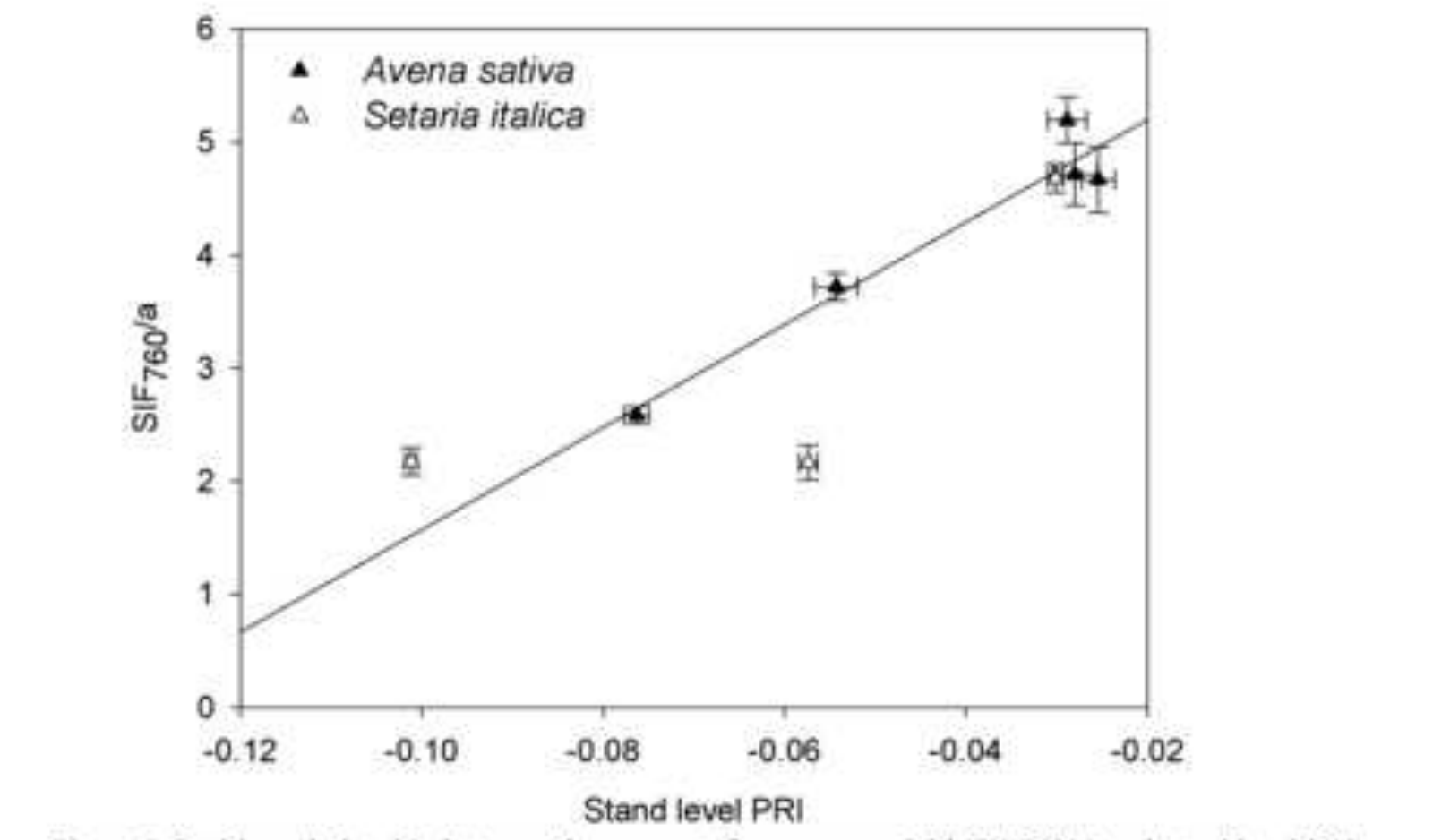

Figure 6. Positive relationship between the apparent fluorescence yield (SIF760/a) and stand level PRI

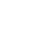

Fure

.

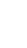

\begin{abstract}
for both species studied (Avena sativa and Selaria ifalica).
Regression equations: SIF $760 / a=5.75+39.92 * P R I, R 2=0.78, p<0.001$. Error bars are $S E(n=10)$.
Regression equations: SIF760/a $=5.75+39.92 * P R I, R 2=0.78, p<0.001$. Error bars are $S E(n=10)$.

Regression equations: SIF 760/a $=5.75+39.92 * P R I, R 2=0.78, p<0.001$. Error bars are $\mathrm{SE}(\mathrm{n}=10)$
\end{abstract}

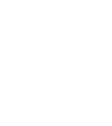

.
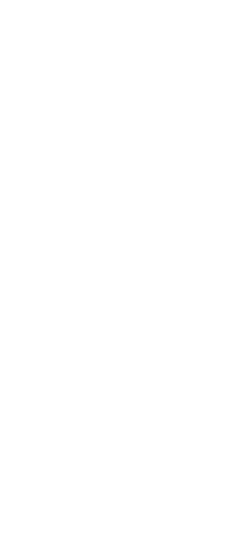


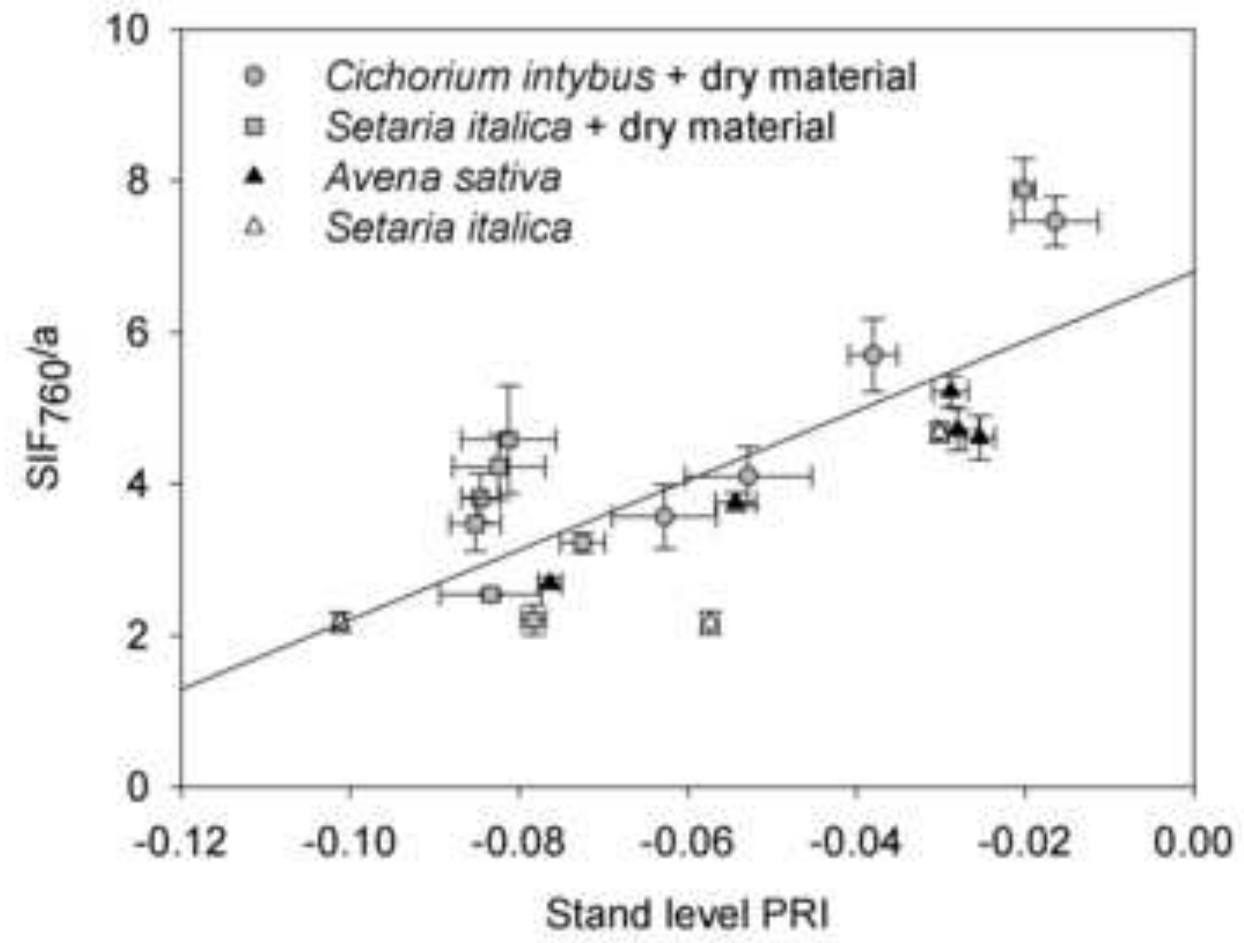

Figure 7. Positive relationship between the apparent fluoresoence yield (SIF 760/a) and stand level PRI for both species studied, Avema sativa and Setaria italica, together with data from the canopies of Cichurium intybus and Setaria italica with increasing proportion of dry plant material incorporated. Regression equation: SIF 760/a $=6.8+45.9 *$ PRI, $R 2=0.59, p<0.001$, Error bars are $S E(n=3)$. 


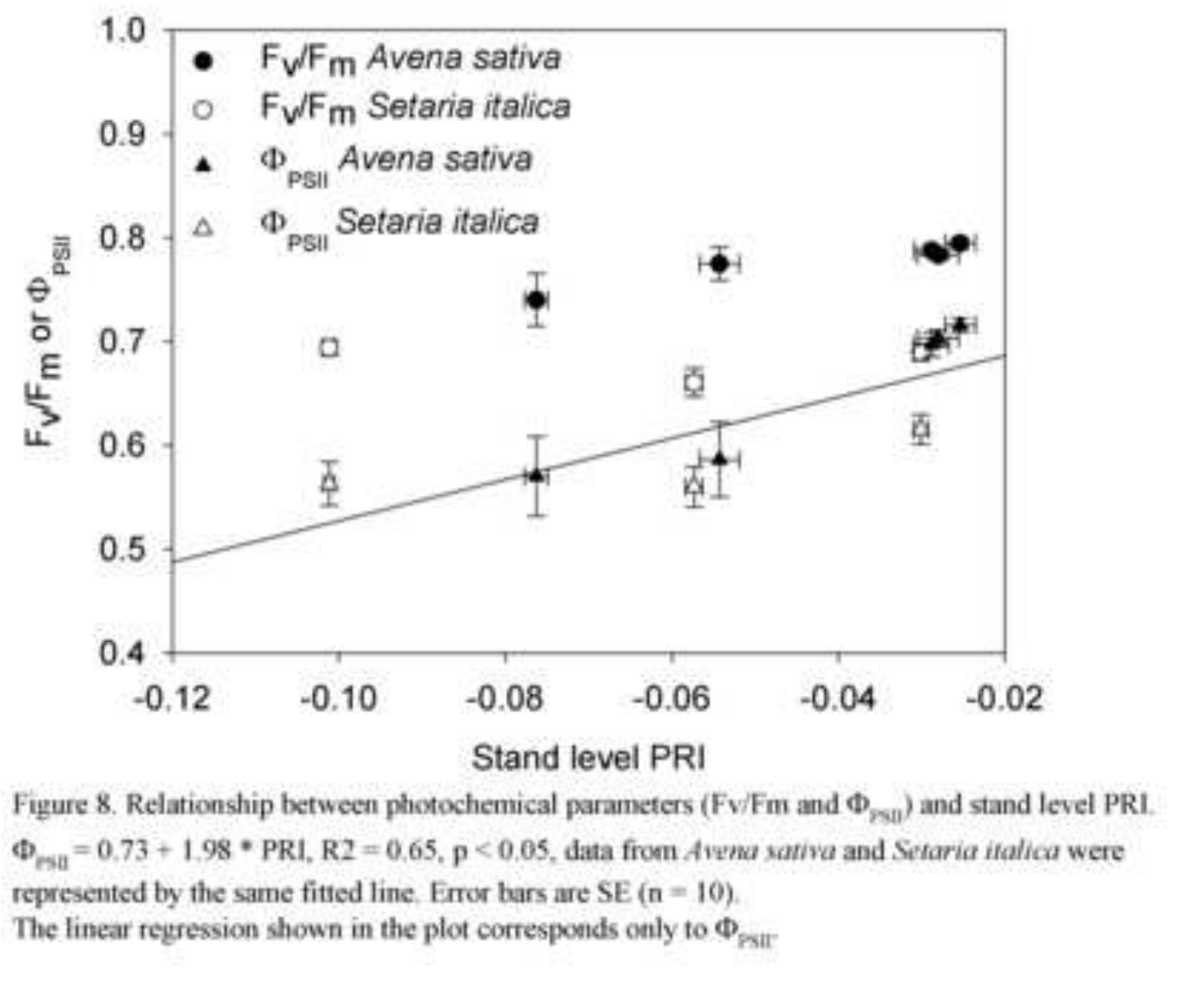

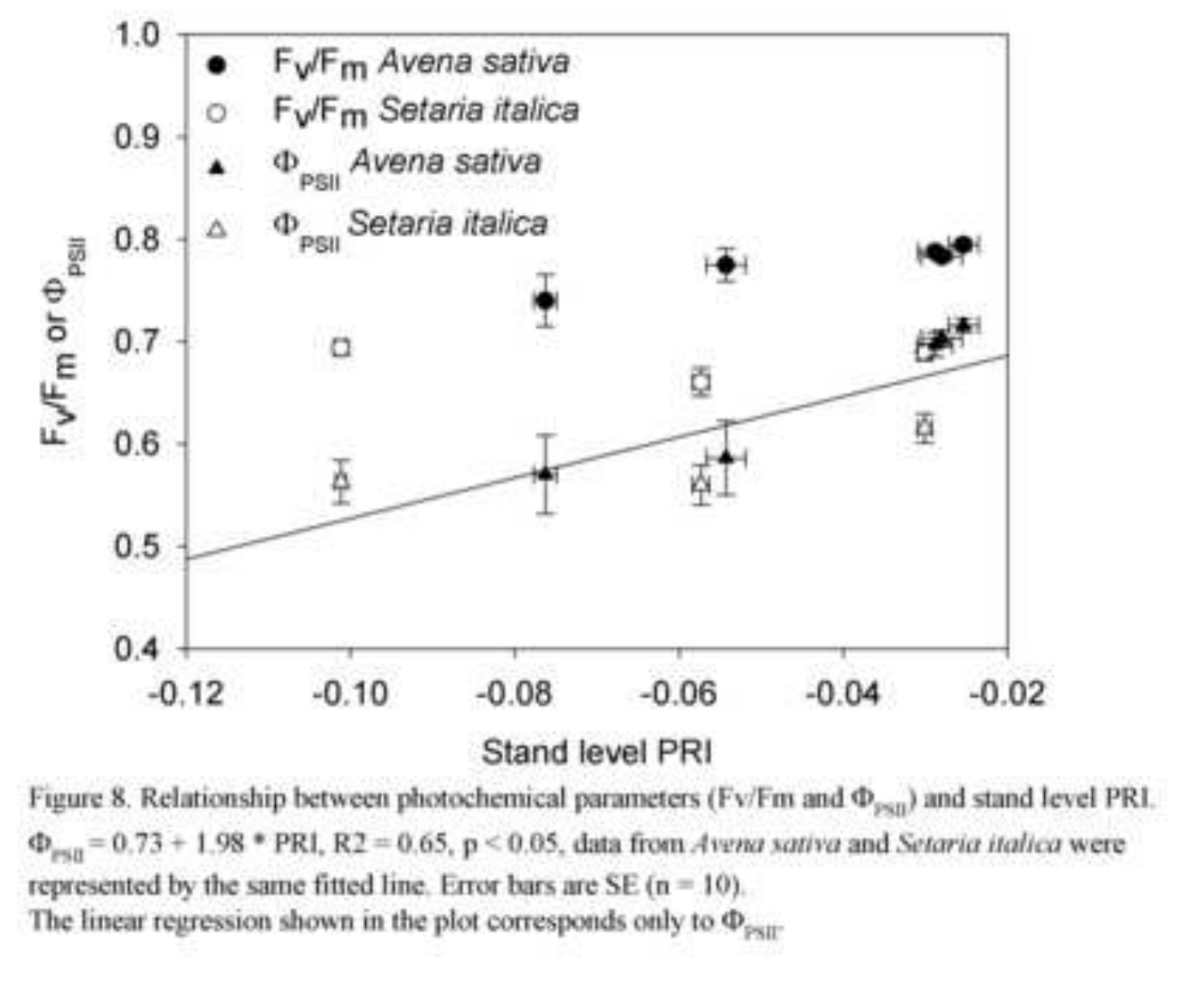

Figure 8. Relationship between photochemical parameters (Fv/Fm and $\Phi_{\text {rsa }}$ ) and stand level PRI.

$\Phi_{\text {nad }}=0.73+1.98 \cdot$ PRI, R2 $=0.65, p<0.05$, data from Avena sativa and Setaria ilalica were represented by the same fitted line. Error bars are $\mathrm{SE}(\mathrm{n}=10)$.
The linear regression shown in the plot corresponds only to $\Phi_{\mathrm{prat}}$

represented by the same fitted line. Enror bars are $\mathrm{SE}(\mathrm{n}=10)$.
The linear regression shown in the plot corresponds only to $\Phi_{\text {part }}$

.

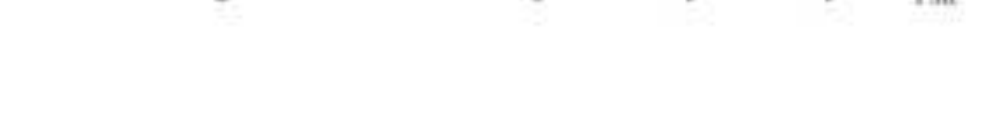

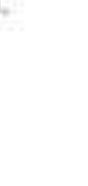




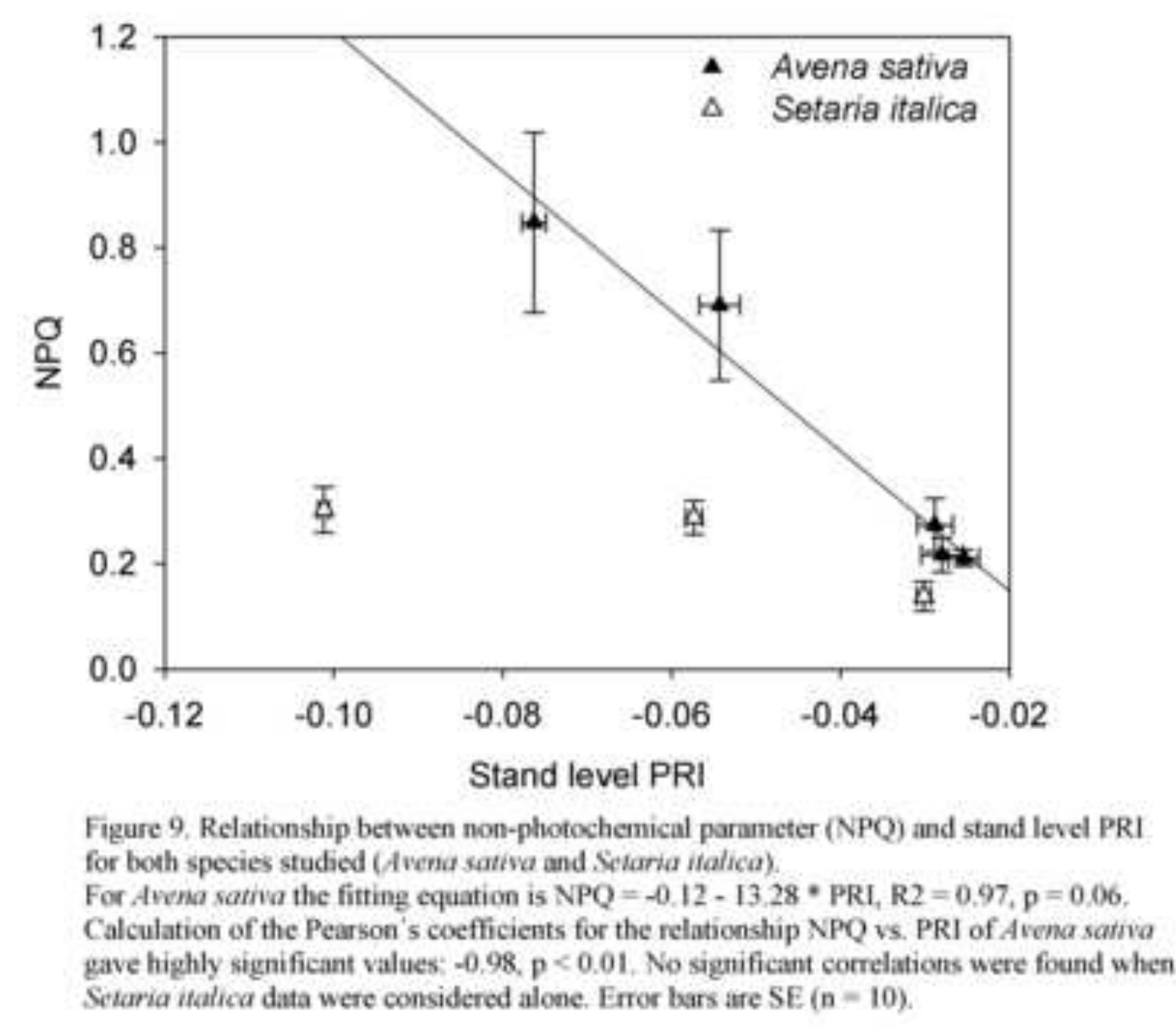

Figure 9, Relationship between non-photochemical parameter (NPQ) and stand level PRI for both species studied (Avena sativa and Sctaria ilalica).

For Avria satria the fitting equation is $\mathrm{NPQ}=-0.12-13,28 * \mathrm{PRI}, \mathrm{R2}=0.97, \mathrm{p}=0.06$. Calculation of the Pearson's coefficients for the relationship NPQ vs. PRI of Avena satria gave highly signifieant values: $-0.98, p<0.01$. No significant correlations were found when Setaria ilatica data were considered alone. Error bars are SE $(n=10)$. 
Table 1. Pearson's correlation coefficients obtained for the linear correlations between optical indices, sun-induced fluorescence and photosynthetic parameters at stand and leaf level. Data from both species were analyzed together.

\begin{tabular}{lcccccccccc} 
& $\mathrm{SIF}_{760} / \mathrm{a}$ & sPRI & sNDVI & Fv/Fm & $\Phi_{\mathrm{PS} 2}$ & $\mathrm{qP}$ & NPQ & IPRI & INDVI & Chl \\
\hline sPRI & $0.88^{*}$ & & & & & & & & & \\
sNDVI & 0.45 & 0.60 & & & & & & & & \\
\hline Fv/Fm & 0.66 & 0.48 & -0.10 & & & & & & & \\
$\Phi_{\mathrm{PS} 2}$ & $0.89^{*}$ & 0.82 & 0.43 & 0.82 & & & & & & \\
qP & -0.42 & -0.06 & -0.25 & -0.21 & -0.38 & & & & & \\
NPQ & -0.41 & -0.48 & $-0.92^{*}$ & 0.19 & -0.39 & 0.46 & & & & \\
lPRI & 0.82 & 0.77 & 0.13 & 0.71 & 0.69 & 0.04 & 0.08 & & & \\
INDVI & -0.39 & -0.34 & -0.13 & -0.57 & -0.70 & 0.47 & 0.32 & -0.07 & & \\
Chl & 0.49 & 0.40 & -0.18 & $0.83^{*}$ & 0.60 & 0.10 & 0.34 & 0.75 & -0.16 & \\
Chl/Car & 0.60 & 0.60 & -0.08 & $0.89^{*}$ & 0.77 & 0.12 & -0.20 & 0.73 & -0.50 & $0.86^{*}$ \\
\hline
\end{tabular}

Correlations obtained with $p<0.05$ or better between different functional groups of the indices are shaded and marked as * when $p \leq 0.01$. sPRI are the values of PRI at stand level and IPRI indicates leaf values of PRI. Chl is the total chlorophyll content $(\mathrm{Chl} \mathrm{a}+\mathrm{Chl} \mathrm{b})$ and $\mathrm{Car}$ is the total carotenoid content (carotenes + xanthophylls). 